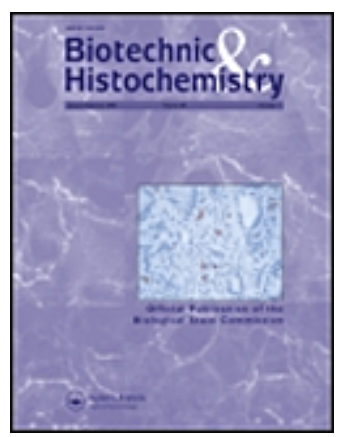

\title{
Use of Dyes to Detect Fingermarks
}

\begin{tabular}{|c|c|}
\hline Journal: & Biotechnic \& Histochemistry \\
\hline Manuscript ID: & TBIH-2009-0081.R1 \\
\hline Manuscript Type: & Review \\
\hline $\begin{array}{r}\text { Date Submitted by the } \\
\text { Author: }\end{array}$ & 26-Oct-2009 \\
\hline Complete List of Authors: & $\begin{array}{l}\text { Becue, Andy; Institut de Police Scientifique, School of Criminal } \\
\text { Sciences } \\
\text { Moret, Sébastien; Institut de Police Scientifique, School of Criminal } \\
\text { Sciences } \\
\text { Champod, Christophe; Institut de Police Scientifique, School of } \\
\text { Criminal Sciences } \\
\text { Margot, Pierre; Institut de Police Scientifique, School of Criminal } \\
\text { Sciences }\end{array}$ \\
\hline Keywords: & $\begin{array}{l}\text { Amino acid, Blood, Detection method, Dye, Fingermark, Fingerprint, } \\
\text { Forensic science, Identification, Lipid, Luminescence, Nanoparticle, } \\
\text { Powder, Trace evidence }\end{array}$ \\
\hline
\end{tabular}

\section{今 scholarONE" \\ Manuscript Central}


Short title: Stains to detect fingermarks

\author{
Address for correspondence: \\ Andy Becue \\ Institut de Police Scientifique \\ School of Criminal Sciences \\ Batochime, University of Lausanne \\ CH-1015 Lausanne, Switzerland \\ Tel: +41(0)216924630 \\ Fax: +41(0)216924605 \\ e-mail: andy.becue@unil.ch
}

URL: http://mc.manuscriptcentral.com/tbih E-mail: biotech-histochem@louisville.eduage 2 


\title{
Use of stains to detect fingermarks
}

\author{
A Becue, S Moret, C Champod, P Margot \\ Institut de Police Scientifique, School of Criminal Sciences, Batochime, University of \\ Lausanne, CH-1015 Lausanne, Switzerland
}

Accepted September 28, 2009

URL: http://mc.manuscriptcentral.com/tbih E-mail: biotech-histochem@louisville.eduage 3 


\begin{abstract}
Detection of fingermarks at a crime scene or on related items is of prime interest for forensic investigators, mainly for identification purposes. Most of the fingermarks are invisible to the naked eye, however, and application of detection techniques is required to establish visual contrast between the secretion residue and the underlying substrate. We give here a review of the field related to the concept of using stains to detect fingermarks. A distinction has been made between the physically driven classical detection techniques, the chemically driven ones, and those based on nanostructured materials, an emerging field in forensic science.
\end{abstract}

Key words: amino acid, blood, detection method, dye, fingermark, fingerprint, forensic, science, identification, lipid, luminescence, nanoparticle, powder, trace evidence 
In a criminal investigation, one role of the forensic scientist is to collect information that permits the identification of people involved in the events. Fingerprints constitute one of the most important items of physical evidence for identification. A fingerprint is defined as a unique pattern present on the fingertips of each individual as well as on the palms and the soles. A fingerprint is characterized by invariability from birth to death, excluding scars and irreversible skin damage that could occur during one's life. In this context, we chose to make a distinction between fingerprints and fingermarks. Fingerprints are physically present on the individual's body and can be inked on a ten-print card to be used for comparison in an identification process. Fingermarks are defined as the secretion residue that is left by a person when a surface is touched with unprotected hands. The origin of this residue is in the pores along the skin surface through which human sweat is excreted. The chemical composition of sweat varies according to the nature of the secreting gland and its location on the body (Ramotowski 2001). In addition, contaminants such as cosmetics or other exogenous components can be present on the fingertips due to contact of bare hands with one's face or fatty food. As a consequence, the composition of the residue that is left on a substrate generally is a complex mixture of organic and inorganic materials dispersed in an aqueous matrix, e.g., amino acids, fatty acids, glycerides, inorganic ions, proteins and esters (Ramotowski 2001). Most importantly, such residue generally is not visible to the naked eye. In such situations the fingermarks are said to be "latent" and the application of detection techniques is required to permit their visualization (Champod et al. 2004). This constitutes a major and continuing challenge for forensic scientists.

We address here the different techniques and reagents used to visualize latent (invisible) fingermarks. The key principle of fingermark detection is simple: to generate as great an optical contrast as possible between the ridges constituting the fingerprint pattern and the underlying substrate without disturbing the pattern formed by the trace. This is necessary 
to ensure efficient visualization of the latent fingermarks, their ridges and their characteristics so they can be used for identification. For white or transparent substrates (e.g., printer paper or polypropylene plastic sheets), good contrast can be obtained readily by staining the residue using dark colored dyes. When dealing with colored, patterned or complex substrates, e.g., magazines, commercial packages and banknotes, however, dyes are not appropriate, and the use of a luminescent stain is necessary to avoid confusion due to the background pattern. The use of luminescence to detect fingermarks also is generally preferred for sensitivity reasons. Actual fingermarks sometimes are composed of extremely small amounts of secretions due to a lack of secretion deposited or to further alterations caused by time and environmental conditions. This makes them difficult to detect when stained with classic chromophores. The luminescence mode, however, increases the sensitivity of detection so that faint fingermarks can be recorded and processed for identification. This also explains why current research projects in the field are directed primarily toward development of new and efficient luminescent detection techniques.

To obtain good contrast, it is necessary for a stain to interact specifically with the secretion residue and not with the underlying substrate (or reciprocally, but this is less often the case). Because the composition of fingermarks varies according to various parameters that forensic scientists cannot control, e.g., sex and age of the donor, storage conditions of the evidence before collection, age of the fingermark, or nature of the substrate, it is necessary to target compounds that are most likely to be found in sufficient quantities in almost all latent fingermarks. Numerous techniques have been developed that target organic and inorganic components with more or less success. Each technique generally is limited in its application according to the type of the substrate and the nature of the secretion. For example, 1,2indanedione and ninhydrin are applied in the case of latent fingermarks on porous surfaces, cyanoacrylate fuming followed by the application of stains is the most efficient approach for 
nonporous ones, physical developer and oil red $\mathrm{O}$ are two techniques for detecting fingermarks when a substrate has been wet, acid yellow 7 and acid violet 17 are specific for blood-contaminated fingermarks, just to cite a few of several situations encountered. These limitations find their origin in the intrinsic interaction mechanisms between the reagents and the secretion residue.

We do not intend to review extensively all the existing fingermark detection techniques. We shall instead provide a broad overview of the historical and routinely used methods as well as the techniques for development. Issues concerning application protocols, formulations, or comparative studies will not be covered. In the context of this review, we shall classify the techniques according to the kind of stain that is used. The reader must appreciate that we have adopted a very broad definition of the term, "stain." We define a stain as any organic molecule, chemical reagent or nanocomposite that permits the visualization of initially latent fingermarks through the creation of a visible contrast between the ridges and the underlying substrate. Note that this view is in keeping with definitions existing in the biological staining literature, such as that of Horobin (1988). The coloration of the secretion residue can be obtained through 1) physical incorporation of stains in the residue itself, e.g., using a lysochrome, 2) chemical reaction between an initially colorless reagent and some components of the secretion residue, e.g., the amino acids, or 3) physico-chemical processes leading to specific targeting of the residue, e.g., negatively charged metal nanoparticles, and its subsequent visualization. Consequently, we begin with stains that color the fingermarks without undergoing a chemical reaction, continue with stains that chemically react with some components of the secretion residue, and finally, describe techniques based on nanostructured materials, a growing field in forensic research. 


\section{Physical detection mechanisms}

By physical detection, we mean colored molecules or particles that have a physical affinity for the fingermarks and permit their visualization without modification of their molecular structure (Voss-de Haan 2006).

Before addressing the issue of stains, it is worth mentioning that it often is possible to detect fingermarks before any treatment of the evidence by using only ambient light and varying the incident angle. Different optical techniques such as episcopic coaxial illumination (Reiss 1903, Pfister 1985, Ziv and Springer 1993), filtered light (Champod et al. 2004), or reflected ultraviolet (UV) light, i.e., the RUVIS system (Saferstein and Graf 2001) can be used to highlight marks on the substrates. Alternatively, some components of the secretions may show an intrinsic luminescence that can be visualized under UV light (Saitoh and Akiba 2005, 2006) or laser illumination (Dalrymple et al. 1977, Menzel 1999). Most of the time, these detection methods suffice when fresh fingermarks, rich in secretion, are laid on nonporous substrates. If the marks are weak, poor in secretion, old, or on a colored substrate, optical techniques must be extended by using stains.

\section{Powder dusting}

Used since the beginning of the last century, powder dusting (Reiss 1911) is one of the first techniques used to detect fingermarks, and it still is widely applied at crime scenes. The principle is simple: powder is dusted onto items using a brush so that it physically adheres to the moist, sticky and greasy substances of fingermark residue (Lee and Gaensslen 2001, Champod et al. 2004). As a result, the contrast between the substrate and the dusted ridges permits observation of the latent fingermarks. This technique is inexpensive and easy to set up, but is limited to smooth and nonporous surfaces. Moreover, only fresh fingermarks give 
satisfactory results; the quality decreases as the fingermarks age owing to a loss of stickiness of their residues, which can be problematic.

Conventional powders generally are composed of a contrasting agent, e.g., metal oxides or chromophoric dyes, plus resinous materials, e.g., stearic acid, for adhesion (Sodhi and Kaur 2001). The first colored dusting powders were obtained by using different metal oxides, sulfides and carbonates, e.g., lead, mercury or antimony. These compounds understandably were abandoned because of toxicity issues. Among the routinely used powders currently, a black one is generally applied on light colored substrates. The black color is obtained by including graphite, powdered charcoal, lamp black or molybdenum powder in their composition. On dark backgrounds, white powders, e.g., titanium dioxide, zinc oxide or zinc sulfide, are preferred (Goode and Morris 1983). Another widely used powder, regarded as one of the most effective (James et al. 1991a), is the so called "argentoratum" (Thomas 1973, 1975) composed of flat aluminium particles and 3-5\% (w/w) stearic acid. Another commonly used preparation is a gold colored powder composed of bronze flakes. As their name indicates, magnetic powders contain a magnetic carrier in addition to a stain. They require the use of a magnetic brush for dusting, thus avoiding destructive contacts between brush hairs and the secretion residue (James et al. 1991b, 1992, 1993). Luminescent powders are used mainly on multicolored backgrounds, when poor contrast might be expected with conventional powders. A great variety of luminescent dyes or pigments are available, e.g., acridine yellow, coumarin 6, or rhodamine 6G (Lee and Gaensslen 2001). Cyano blue dye, Nile red and proflavine also were tested recently as fluorescent dusting components (Sodhi and Kaur 2004, 2005, Kaur 2006).

An alternative way of applying powders is as suspensions in aqueous solution, a method also known as "wet powdering" or "small particle reagent." This technique will be described below. 


\section{Camphor}

Camphor dusting may be considered an unconventional dusting method, because it requires the use of soot freshly obtained by burning it (Waldoch 1993). Camphor is a flammable white crystalline solid that produces a large amount of black soot when burned. The item to be "dusted" is maintained above the burning camphor to allow the black smoke to cover the entire surface. The soot adheres selectively to the fingermark residues and the excess is removed with a brush or under tap water; the fingermark appears black. Camphor may be helpful for some substrates such as firearms cartridges (Sturelle et al. 2006), but is not used for conventional surfaces.

\section{Iodine fuming}

Iodine $\left(\mathrm{I}_{2}\right)$ fuming was described very early (Coulier 1863) for detecting forgeries and fingermarks. A substrate bearing latent fingermarks is exposed to the purple iodine vapors provided by crystals of iodine contained in a glass vessel through which an air stream is forced to pass. The lipids present in the secretions physically absorb the vapors, which results in a temporary yellowish or brownish staining of the marks. Visualization is temporary due to the re-sublimation of iodine vapors from the marks to the ambient atmosphere after a few minutes. It is possible, however, to fix the stained fingermarks by a chemical reaction between iodine and 7,8-benzoflavone ( $\alpha$-naphthoflavone) (Mashito and Makoto 1977, Haque et al. 1983), which results in a permanent blue image. The mark also can be lifted by using the corrosive nature of the iodine. A highly polished silver or tin plate is pressed firmly on the mark for $5 \mathrm{sec}$, then exposed to a strong white light source or UV lamp. This leads to the formation of a dark image on the plate (Adcock 1977, Arndt 1985).

This technique can be applied to various porous and nonporous surfaces, especially on difficult ones like leather or human skin (Adcock 1977, Gray 1978). It should be emphasized 


\section{Lipid dyes: oil red $O$ and solvent black 3}

The lipid fraction of secretion residues constitutes a good target for fingermark detection, because it is possible to dye them specifically using lysochrome molecules currently used in biology. Moreover, in the case of fingermarks that have been wet, it is generally accepted that the water soluble components, e.g., ions, amino acids or proteins, are no longer present on the substrate due to their solubilization, while the water insoluble components, e.g., lipids, remain and can still be retrieved.

Oil red O (ORO; solvent red 27) is a relatively new technique for detecting fingermarks on porous surfaces (Beaudoin 2004, Rawji and Beaudoin 2006, Guigui and Beaudoin 2007). ORO is a lysochrome used in biology to stain lipids and lipoproteins. When a porous substrate bearing latent fingermarks is immersed in the ORO working solution, the fingermarks appear as visible red marks by accumulation of the dye molecules, whereas the substrate generally undergoes a slight coloration (light red) leading to sufficient contrast between the mark and the substrate to permit good visualization (Fig. 1). ORO also is used in forensic science to stain lip marks, especially when lipstick is used (Navarro et al. 2006).

Solvent black 3 (or Sudan black) is another lysochrome used to stain lipids and phospholipids in histochemistry. Very few applications of this dye for fingermark detection have been reported (Hart 2003, Home Office Scientific Development Branch 2005). Solvent black 3 is applied mostly on greasy, contaminated surfaces for which other methods give poor results or fail to detect fingermarks. The marks that are obtained after staining are dark blue. 


\section{Enhancement of cyanoacrylate-developed fingermarks}

Cyanoacrylate fuming cannot really be considered a physical staining method as defined in the introduction, because chemical processes take place with the secretion residue. This detection technique, however, generally is combined with a subsequent dyeing step, which does fall into this category.

Cyanoacrylate fuming, a method used worldwide, was developed toward the end of the 1970's (Lee and Gaensslen 1984) to detect fingermarks on nonporous surfaces. It involves the use of a colorless monomeric liquid, i.e., the cyanoacrylate ester (also known as Superglue, a rapid bonding, high strength glue) heated to its boiling point. Monomeric vapors are produced that react with some components of fingermarks by polymerization (Fig. 2), but not with the underlying substrate. The exact initiators of the polymerization are not yet clearly determined, because cyanoacrylate shows particular affinity for moisture, lipids and some water soluble components (Lewis et al. 2001, Wargacki et al. 2007). As a result of the polymerization process, which continues until the source of monomers is removed or the heating process is stopped, a white solid covers the developed fingermarks (Mankidy et al. 2006). At the microscopic level, polycyanoacrylate is not a massive and continuous film that covers the secretion residue, but rather can be described as tangled noodles. Owing to the toxicity of the vapors (Hughes 1993), treatment is performed in a cabinet where humidity and heating of the cyanoacrylate can be controlled precisely.

Cyanoacrylate fuming is a sensitive technique for detecting fingermarks on nonporous surfaces The contrast obtained, however, sometimes is poor due to the white color of the polymer (Fig. 3), which results in barely visible or undetected fingermarks. Fortunately, cyanoacrylate-developed fingermarks can be stained using organic dyes that are trapped selectively in the polymer network and this significantly enhances the visual contrast (Fig. 3) 


\section{Chemical detection techniques}

By chemical detection, we mean generally uncolored staining reagents that undergo chemical reaction, i.e., modifications of their molecular structure, with some components of the fingermarks to produce colored or luminescent compounds.

\section{Silver nitrate}

A reagent that must be cited for historical reasons is silver nitrate $\left(\mathrm{AgNO}_{3}\right)$. This was first used in 1878 to detect chloride ions contained in papillary secretions (Aubert 1877-1878, Olsen 1978). This method can be applied on porous surfaces including paper and untreated wood. The principle is simple: silver nitrate reacts with the chloride ions contained in the secretion residue to form silver chloride $(\mathrm{AgCl})$. Upon exposure to light, $\mathrm{AgCl}$ decomposes to form metallic silver $(\mathrm{Ag})$, resulting in a black fingermark. Owing to the diffusion of chloride ions through the substrate, however, blurred fingermarks are obtained if they are aged more than one week. The kinetics of the diffusion has been studied to try to determine the age of the fingermark (Angst 1962). 


\section{Amino acid reagents}

Amino acids constitute a major organic component of sweat; $0.3-2.59 \mathrm{mg}$ of amino acids are secreted per liter of sweat (Ramotowski 2001), which corresponds to 2.4-20.7 $\mu \mathrm{M}$ for a typical amino acid. Amino acids, therefore, represent a specific target for a fingermark detection strategy based on chemical reaction. Amino acid detection (or quantification) agents used in biology, such as ninhydrin, have been applied successfully in forensic science as described below.

Amino acids generally, unlike chloride ions, show strong affinity for paper fibers, and their migration through such substrates is prevented. Fingermarks thus are well preserved in the paper matrix and can be detected satisfactorily tens of years after deposition. Note also that amino acids typically are water soluble constituents of sweat. This means that if the item has been wet, such compounds will not be recovered and the following techniques could not be successfully applied.

Ninhydrin (2,2-dihydroxy-1,3-indanedione) was the first amino acid reagent used for detecting latent fingermarks on porous surfaces such as paper and cardboard (Odén and Von Hofsten 1954) and it still is widely used. Ninhydrin can detect primary and secondary amines contained in amino acids or in polypeptides present in latent fingermarks. When reacting in situ with such free amines, ninhydrin produces a deep blue or purple product, Ruhemann's purple (Fig. 5). As a result, fingermarks appear as purple ridges on unmodified substrate (Fig. 6). Several studies have been performed to improve the sensitivity and to optimize the development conditions over wider temperature and relative humidity ranges (Lamothe and McCormick 1972, Grigg et al. 1986, Lennard et al. 1986, Almog 2001, Petraco et al. 2006).

Despite the great sensitivity of ninhydrin, the contrast between the fingermark and the substrate can be weak, e.g., on dark backgrounds. In this case, observation of the fingermarks is impossible, because Ruhemann's purple is not luminescent. Efforts have been made to 
overcome this problem, especially by using post-ninhydrin treatments containing metal salts. When Ruhemann's purple is reacted with zinc or cadmium ions, luminescent coordination complexes are formed. As a result, fingermarks undergo a color change and become orange instead of purple with zinc and red instead of purple with cadmium. The derivatives also exhibit luminescence when cooled to $77 \mathrm{~K}$ with liquid nitrogen (Kobus et al. 1983, Stoilovic et al. 1986, Lennard et al. 1987). Cadmium toxicity and the inconvenience of storing liquid nitrogen, however, are drawbacks limiting application of such post-treatments. Extensive research has been carried out to discover ninhydrin-like reagents with increased sensitivity and room temperature luminescence (Almog et al. 1982, 1992, 2000, 2001, Lennard et al. 1986, 1988, Joullié et al. 1991, Hansen and Joullié 2005). Many ninhydrin analogues have been synthesized and studied, but despite this, few have been used routinely for reasons of expense and time-consuming synthesis protocols.

Another amino acid reagent that has been used widely for nearly 20 years is 1,8 diazafluoren-9-one (DFO) (Wilkinson 2000b). Unlike ninhydrin, DFO produces very faint pink fingermarks, barely visible to the naked eye, but which are extremely luminescent at room temperature (Grigg et al. 1990, McComiskey 1990, Pounds et al. 1990).

More recently, a third amino acid reagent, 1,2-indanedione, has been shown to be effective for detecting fingermarks on porous surfaces. When using 1,2-indanedione, pink colored fingermarks characterized by strong luminescence at room temperature are obtained (Fig. 7). Extensive comparative studies showed that 1,2-indanedione is an alternative to DFO (Joullié et al. 1998, Roux et al. 2000, Wilkinson 2000a, Wiesner et al. 2001, Kasper et al. 2002, Gardner and Hewlett 2003). Recent research also has shown that when zinc chloride $\left(\mathrm{ZnCl}_{2}\right)$ is introduced to the 1,2-indanedione working solution before treating the specimen, the luminescence of the detected fingermarks is markedly improved (Stoilovic et al. 2007, Wallace-Kunkel et al. 2007, Bicknell and Ramotowski 2008, Russell et al. 2008). For these 
reasons and others, such as faster detection procedure, DFO is being replaced by 1,2indanedione in the forensic laboratory for detecting fingermarks on porous surfaces.

Concerning the mechanisms of the reactions between amino acids and the reagents above, a recent study showed that the reactions between DFO or ninhydrin and all the amino acids go to completion (Spindler et al. 2009). This is not the case with 1,2-indanedione, however, which varies according to the amino acid involved. The addition of a small amount of zinc to the working solution seems to play a role in the completeness of the reaction, because zinc acts as a catalyst.

Two other less widely used reagents for amino acids also are used. Genipin is a natural product extracted from Gardenia jasminoides. Upon reacting with amino acids, a blue reaction product is obtained that gives a red luminescence at room temperature (Lee et al. 2003, Almog et al. 2004, Levinton-Shamuilov et al. 2005). This reagent constitutes the only "dual fingermark reagent" for amino acids, i.e., a reagent giving visible/colored fingermarks that also can be observed with luminescence. Genipin has the further advantage of being a natural and nontoxic product. Lawsone (2-hydroxy-1,4-naphthoquinone) is the compound thought to be responsible for the staining properties of henna, commonly used as a skin and hair dye. In forensic science, naphthoquinones represent a new group of compounds that can be used to detect the amino acids (Jelly et al. 2008). After treatment with lawsone, fingermarks are stained purple-brown and exhibit a strong red luminescence. Currently, only experimental results are available and further research is needed before considering it an effective reagent.

\section{p-4-Dimethylaminocinnamaldehyde (pDMAC)}

Urea is another component of sweat that could be targeted to detect fingermarks on porous surfaces. The first reagent proposed for this purpose was p-4-dimethylaminocinnamaldehyde 


\section{Osmium tetroxide and ruthenium tetroxide}

Osmium tetroxide $\left(\mathrm{OsO}_{4}\right)$ and ruthenium tetroxide $\left(\mathrm{RuO}_{4}, \mathrm{RTX}\right)$ are compounds that can react with the double bonds of the unsaturated organic compounds found in a fingermark deposit through an oxidation mechanism (Grzegorzewska and Filbrandt 2004). Direct exposure to $\mathrm{OsO}_{4}$ vapors provides black fingermarks after 1 to $12 \mathrm{~h}$ (Olsen 1978), whereas RTX gives gray marks after only 10 to 20 min (Mashiko et al. 1991, Mashiko and Miyamoto 1998). Despite the excellent results that can be obtained on a variety of surfaces, especially the problematic ones like human skin, $\mathrm{RTX}$ and $\mathrm{OsO}_{4}$ are not used routinely because of their high toxicity through inhalation or skin contact and hazards associated with their manipulation (Blackledge 1998). Only fully equipped laboratories can consider their use.

\section{Fingermarks in blood}

When the victim and/or the offender are injured, hands can become contaminated with blood. In such cases, bloody fingermarks are likely to be recovered. Depending on the amount of blood and on the nature of the substrate, some marks are obvious to the naked eye, but others remain latent and require the application of specific blood reagents. 
Although two different categories of blood reagents exist, viz., protein stains and heme reagents, blood sometimes can be visualized directly due to a strong absorption at $415 \mathrm{~nm}$ (Stoilovic 1991) that makes it appear black under illumination at this wavelength. Blood also can be observed due to luminescence in the long-wave UV region when short-wave UV exciting light is used (Springer et al. 1994). Before using any blood-specific reagent, the items bearing latent fingermarks generally are dipped in methanol or in an aqueous 5-sulfosalicylic acid solution $(2 \% \mathrm{w} / \mathrm{v})$ to avoid loss or diffusion of blood due to the water-based blood reagents (Hussain and Pounds 1988, Sears and Prizeman 2000). Once fixed, effective blood reagents can be applied.

Protein stains are compounds adopted directly from biology. The application protocol consists of immersing the item to be treated in a dye solution. The staining times vary from 10 sec to several minutes depending on the dye, the type of substrate and the amount of blood. The dye binds to the proteins, which leads to a colored or luminescent complex. The item then is washed with successive de-staining solutions, based on methanol or water, to remove the excess dye and to clear the background so that contrast is improved (Fig. 8). Because numerous protein stains can be applied, only the commonly used ones are noted here (Sears and Prizeman 2000, Sears et al. 2001, 2005, Marchant and Tague 2007). A conventional nonluminescent stain is amido black (naphthol blue black B), which gives dark blue marks on light blue or nearly colorless substrates. Luminescent stains also are available, e.g., acid yellow 7, acid fuchsine (Hungarian red) and acid violet 17 (Coomassie brilliant violet). Which dye is used depends on the color and the nature of the substrate.

Heme reagents are molecules that can undergo oxidation, initiated by hydrogen peroxide in presence of a catalyst, in this case the heme group of hemoglobin. As a result, colored, luminescent, or chemiluminescent (a product generating its own light with no need to use excitation light source) products are formed. The reaction is selective for blood (possible 
false positive results are not discussed here) and gives little background staining. Routinely used stains include 3,3-diaminobenzidine (DAB) (Allman and Pounds 1991, 1992, Sahs 1992), which gives a dark brown color; ABTS (2,2'-azino-di-(3-ethylbenzthiazolinesulfonate) diammonium salt) (Caldwell et al. 2000), which gives a green reaction product; and leucomalachite green, phenolphthalein, leucocrystal violet, o-tolidine (Lee 1984), fluorescein (Cheeseman and DiMeo 1995), leuco rhodamine 6G (Yapping and Yue 2004) or eosin Y (Wang et al. 2007). Another heme reagent that must be cited, even if it is not used as a fingermark reagent, is luminol. This gives rise to intense blue chemiluminescence and is used to detect traces of blood as might be found on a crime scene or on items that have been washed (Webb et al. 2006). Any fingermarks that are obtained, however, are not sufficiently sharp to detect fingerprint ridges that are necessary for identification of the person, and the procedure is used only to detect the presence of blood, which facilitates subsequent blood sampling for DNA analysis.

Finally, note that the conventional fingermark reagents, e.g., amino acid reagents or cyanoacrylate, also can detect blood fingermarks even if they do not possess the sensitivity of the specific blood reagents. Conventional stains, therefore, generally are applied before the blood reagents to detect most of the existing bloody or non-bloody fingermarks.

\section{Nanoparticles - a new generation of stains}

During the last decade, considerable interest has emerged within the forensic science community in using nanoparticles or nanocomposites for detecting fingermarks. Nanoparticles already are applied successfully in cell and whole animal imaging (Bagwe et al. 2003, Medintz et al. 2005, Michalet et al. 2005, Murcia and Naumann 2005, Thurn et al. 2007), but constitute an emerging field in forensic science. 
Interest in nanoparticles to detect fingermarks is due to their properties: 1) their size is 1,000 to 10,000 times smaller than a fingerprint ridge width, which ensures excellent resolution upon detection, 2) their structure can be modified easily by addition of molecular chains or chemical functionalities on their outer surface, and 3) their optical properties make them excellent candidates for obtaining luminescent fingermarks. Nanoparticles such as quantum dots are intrinsically luminescent (Bawendi et al. 1990, Wang and Herron 1991, Murray et al. 1993), and others, e.g., silica nanoparticles, are made luminescent by incorporating organic dyes in their structure during their synthesis.

The challenge for using nanoparticles to detect fingermarks lies in the fact that nanoparticles per se generally have no specific affinity for the marks. It is necessary, therefore, to find a way to make nanoparticles specifically target the secretion residues without acquiring an affinity for the substrate; otherwise the resulting contrast would be poor (Fig. 9). A successful application of nanoparticles generally is obtained by adding functional groups onto the nanoparticles (Fig. 10) or by modifying the experimental conditions, such as the $\mathrm{pH}$, to influence parameters such as the charge on the nanoparticle.

The following sections describe four approaches that were selected for their specificity in terms of fingermark detection processes: physico-chemical detection, lipid-lipid interaction, and electrostatic interaction.

\section{Metal nanoparticles}

Use of metal nanoparticles to detect fingermarks on various kinds of substrates has interested forensic scientists for several years (Choi et al. 2008b). Both in terms of research and practical applications, most interest has focused on two kinds of metal nanoparticles, gold and silver. The multimetal deposition technique (based on gold nanoparticles) and physical development (based on silver nanoparticles) are not new; both were developed in the 1980s. Research 


\section{Multimetal deposition (MMD)}

Gold nanoparticles conventionally are synthesized in water. A gold (III) derivative (generally, tetrachloroauric acid; $\mathrm{HAuCl}_{4}$ ) is reduced using an agent such as sodium citrate or sodium borohydride. The reduction of $\mathrm{HAuCl}_{4}$ by sodium citrate in boiling water is one of the most commonly used procedures for obtaining monodisperse spherical gold nanoparticles, generally about $10-20 \mathrm{~nm}$ diameter, with time stabilities of several months to years (Turkevich et al. 1951, Frens 1973, Slot and Geuze 1981, Turkevich 1985a,b). The origin of such excellent stability is to be found in the capping of the gold nanoparticles in solution by tri-negatively charged citrate ions. The electrostatic repulsion of the resulting negatively charged nanoparticles prevents them from aggregating. The same negative charge also is the basis of their ability to detect fingermarks by exploiting charges on organic components such as proteins, amino acids and lipids as latent prints deposited on a substrate.

If a sample bearing a fingermark is immersed in an aqueous solution of freshly prepared colloidal gold ( $\mathrm{pH} \sim 6.2$ ), nothing happens. If the $\mathrm{pH}$ of the colloidal solution is lowered beforehand, however, it is possible to find a small range of $\mathrm{pH}$ for which both of the following conditions are met. 1) The tri-negatively charged citrate ions are not yet fully protonated $\left(\mathrm{pKa}_{1}=3.13, \mathrm{pKa}_{2}=4.76, \mathrm{pKa}_{3}=6.40\right)$ and still give the gold nanoparticles a negative charge. It should be noted that the interaction of carboxylic groups with a metal surface, as is the case with sodium citrate and gold, can lead to a decrease of the pKa values (increasing acid strength of the groups) measured for the same molecule in solution 
(Królikowska and Bukowska 2007). 2) The proteins and amino acids that are entrapped in the residue become progressively more positively charged due to the protonated amino groups ($\mathrm{NH}_{3}{ }^{+}$). These positive charges are progressively less counterbalanced by the carboxylate groups $\left(-\mathrm{COO}^{-}\right)$as they become protonated to neutral carboxylic moieties (-COOH) at low $\mathrm{pH}$.

In the case of fingermarks, the range of $\mathrm{pH}$ is extremely narrow and has been determined experimentally as 2.5-2.8 (Schnetz and Margot 2001). When the pH of colloidal gold is within this range and a sample bearing a fingermark is dipped in it, negatively charged gold nanoparticles in solution become attracted electrostatically by the positively charged residue. Above this range, proteins are not sufficiently positively charged; below this range, gold nanoparticles become uncharged by complete protonation of the sodium citrate ions (the solution turns dark purple as the gold nanoparticles aggregate owing to lack of electrostatic repulsion). This mechanism of staining selectivity is intriguingly like that of acid dyeing of proteins in biological staining (Horobin 1988) and textile dyeing (Zollinger 2003).

These physico-chemical considerations are the basis of the MMD technique, (Fig. 11). MMD was developed in 1989 (Saunders 1989) and improved in 2001 (Schnetz and Margot 2001). This technique is based on the electrostatic attraction between the gold nanoparticles and secretions when the $\mathrm{pH}$ of the colloidal gold is adjusted to 2.65. Fingermarks detected by gold nanoparticles only, however, are not readily visible to the naked eye, because they produce very faint pink marks due to the small size of the nanoparticles. To increase the contrast, a second metal deposition is performed by reducing silver ions to metallic silver on the surface of the gold nanoparticles, which play the role of catalytic sites. As a result, fingermarks appear dark brown as illustrated in Fig. 12. MMD is an efficient technique for a wide range of substrates, e.g., porous, nonporous and wet, but it is highly labor intensive and produces dark brown marks only. 
An alternative to MMD was proposed in 2007, the single metal deposition (SMD) (Stauffer et al. 2007, Durussel et al. 2009). The procedure is similar to MMD, except that the enhancement step, i.e., second metal deposition, is performed by reducing gold ions instead of silver onto the gold nanoparticles. The results obtained with SMD are similar to MMD (Fig. 12), but the overall procedure is cheaper, less labor intensive, and easier to set up.

Both MMD and SMD produce dark brown fingermarks. This means that the contrast can be very good on transparent, white or light colored substrates, but these techniques fail to produce sufficient contrast on dark colored or patterned substrates for which purpose luminescence is required. A modification of the enhancement step led to the formation of a zinc oxide shell instead of silver or gold around the gold nanoparticles after they were deposited on the secretion residue (Becue et al. 2008). In this way, luminescent fingermarks were obtained on dark, nonporous substrates (Fig. 12). This technique currently is limited to nonporous surfaces, however, unlike MMD and SMD, which can be applied on porous and nonporous substrates.

\section{Physical developer}

Use of a physical developer (PD) is another detection technique based on metal nanoparticles and driven by physico-chemical mechanisms (Goode and Morris 1983). Unlike MMD, for which metal colloids were synthesized prior to the development procedure, PD consists of immersing samples bearing fingermarks in an acidic aqueous solution containing silver ions e.g., silver nitrate; reducing agents, e.g., ferrous and ferric ions; positively charged ionic surfactant, e.g., n-dodecylamine acetate; and other chemical components such as citric acid to lower the $\mathrm{pH}$ of the solution. The accepted mechanism is that during the reduction process, negatively charged silver colloids are formed by reduction of the silver ions (Cantu 2001, Cantu and Johnson 2001). If such silver nanoparticles are formed in solution, they are 
surrounded rapidly by positively charged surfactant molecules, which prevent silver colloids from aggregating and stops particle growth (Fig. 13). Such nonreactive nanoparticles do not play a role in fingermark detection and remain in solution. If the negatively charged silver colloids are formed near a fingermark, however, they immediately become attracted by the positively charged residue because the $\mathrm{pH}$ of the solution is lowered to the acidic range. Once entrapped in the secretion, these silver colloids act as reduction sites for the additional silver ions. As a result, fingermarks become progressively visible as the reduction process continues. At some point, the forensic scientist stops the process by removing the sample from the reducing bath and by dipping it in a neutralizing/rinsing water bath. The fingermarks obtained are a gray color (Fig. 13). Like MMD, PD is applied to white colored substrates only.

\section{Other applications of metal nanoparticles}

In the cases of MMD, SMD and PD, metal nanoparticles are used without further surface modifications; the detection is driven by physico-chemical mechanisms and especially electrostatic interactions. Another strategy involves functionalizing the metal nanoparticles with nonpolar hydrophobic aliphatic chains (Fig. 14) so that they can be applied in suspension in organic solvents (Sametband et al. 2007) or as enhanced nanopowders once dried and dusted using a brush (Choi et al. 2006, 2008a). The addition of aliphatic chains to the nanoparticles enhances the interactions between the metal nanoparticles and the lipids contained in the fingermark residue (Choi et al. 2008b). Compared to classical (micro-sized) powders, nanopowders have been shown to give better results in terms of ridge details and less unwanted deposition on the underlying substrate. Despite this, the use of nanopowders did not necessarily lead to a better contrast, because the detected fingermarks were a lighter color than the dark colored classical powders. 
Another research strategy consisted of binding antibodies onto gold nanoparticles to take advantage of the highly selective antibody-antigen recognition process to detect specific drug metabolites in a fingermark (Leggett et al. 2007). In an attempt to provide evidence of the consumption of a drug in addition to touching contaminated objects, anti-cotinine antibodies bound to gold nanoparticles have been used to target cotinine, a metabolite of nicotine, present in the sweat of tobacco smokers. Combined with a fluorescent marker, highly detailed fingermarks can be observed on glass slides (Fig. 15). Another research strategy is immunolabeling to identify antigenic sites with the secretion residue components or keratinized skin. Proteins present in sweat or skin remnants that have been identified in this way are keratins 1 and 10, cathepsin D and dermcidin using the corresponding antibodies (Drapel et al. 2009).

\section{Metal Oxide nanoparticles}

Nanopowder and small particle reagents

Metal oxides have been widely used for detecting fingermarks due to their optical properties, i.e., color and fluorescence, because it is possible to obtain both white particles, such as titanium dioxide $\left(\mathrm{TiO}_{2}\right)$ or zinc oxide $(\mathrm{ZnO})$, and also black particles, such as iron oxide $\left(\mathrm{Fe}_{2} \mathrm{O}_{3}\right)$. Such reagents can be used as conventional fingerprint powders or they can be suspended in aqueous media using a detergent to enhance their solubility. As a result, one can detect fingermarks on nonporous substrates or on the adhesive side of tapes using a process that has been described as a "wet version of the classical powdering process" or "wet powdering" (Cucè et al. 2004, Williams and Elliot 2005). Instead of using a brush, samples are treated by immersing them in particle suspensions before rinsing with water. Fingermarks are detected by entrapment of the metal oxide particles in the lipid matrix of the secretion residue. This technique uses "small particle reagents" (SPR) and gives good results with 
nonporous substrates on which latent fingermarks are present, especially if the substrate has been wet (Goode and Morris 1983, Frank and Almog 1993, Champod et al. 2004). In addition to the metal oxide particles noted above, black molybdenum sulfide $\left(\mathrm{MoS}_{2}\right)$ and white zinc carbonate $\left(\mathrm{ZnCO}_{3}\right)$ particles also are used as SPR agents. According to the color of the underlying substrate, white powder, e.g., $\mathrm{TiO}_{2}$, or black powder, e.g., $\mathrm{Fe}_{2} \mathrm{O}_{3}$, is used to maximize the contrast. A luminescent version of SPR has been proposed that involves addition of luminescent organic dyes, e.g., basic yellow 40 in ethanol, to a conventional aqueous SPR solution (Springer and Bergman 1995, Lee and Gaensslen 2001, Jasuja et al. 2008).

The size of the particles influences the result of SPR; smaller particles give better results than larger ones (Frank and Almog 1993). As for dried nanopowders, the use of nanoparticles in the context of SPR can greatly improve the resolution.

More recently, nanostructured $\mathrm{ZnO}$ was used to detect fingermarks on nonporous surfaces by taking advantage of its visible fluorescence when dry dusted or applied as an SPR (Choi et al. 2008a). These investigators combined oleylamine with the fluorescent dye, perylene dianhydride, to form an entity that then was adsorbed onto $\mathrm{TiO}_{2}$ nanoparticles to form a powder exhibiting strong fluorescence at $650-700 \mathrm{~nm}$ when excited at $505 \mathrm{~nm}$ (Choi et al. 2007). When dusted onto nonporous substrates bearing latent fingermarks, this fluorescent nanopowder was slightly weaker in fluorescence intensity compared to conventional luminescent powders, but produced significantly less background. As a result, good contrast was obtained between the fingermarks and the substrate.

Titanium dioxide as a blood reagent 
Sub-micron titanium dioxide particles suspended in anhydrous methanol can be used to detect blood fingermarks on nonporous and "semiporous" surfaces (Bergeron 2003). The results were excellent on nonporous surfaces. No mechanistic explanation was offered for the affinity of $\mathrm{TiO}_{2}$ for blood. Uptake, however, may be related to the fact that $\mathrm{TiO}_{2}$ has some affinity for blood (Nygren et al. 1997) and for proteins by electrostatic interactions (Topoglidis et al. 2001).

\section{Quantum dots (QDs)}

QDs are crystalline semiconductor nanoparticles containing a few hundred to several thousand atoms varying in size from 1 to $10 \mathrm{~nm}$. Owing to quantum confinement, QDs exhibit strong luminescence at room temperature. It is of interest that the emission wavelength is dependent on the size of the nanoparticle; larger nanoparticles emit in the infrared/red range and smaller ones emit in the ultraviolet/blue range of the spectrum. Another significant feature of such nanoparticles is the fact that all the QDs have a broad excitation spectrum in the ultraviolet range. This means that a variety of QDs, each emitting its own wavelength, can be excited by a single excitation source. These nanoparticles are used in a wide variety of applications such as components for lasers (Bukowski and Simmons 2002) or as fluorescent probes for cellular imaging (Medintz et al. 2005). QDs high quantum yield and ability to resist photobleaching make them superior markers compared to organic fluorescent dyes (ReschGenger et al. 2008). QDs can be synthesized in either water or organic solvents depending on their external surface coating. Moreover, their outer surface can be functionalized easily with chemical groups to provide new functionalities. Consequently, QDs are widely used in cell biology to stain different components of cells or tissues (Bruchez et al. 1998).

In forensic sciences, particularly for fingermark detection, the properties of QDs are stimulating great interest. Their surfaces can be coated specifically to target the secretion 
residue and the luminescence emission color can be tuned in case of a luminescent background. Since 2000, several studies have focused on the use of QDs to detect fingermarks. Cadmium sulfide (CdS) nanocrystals, used alone or combined with dendrimers, i.e., hyperbranched polymers, have been proposed as stains for cyanoacrylate-developed fingermarks (Bouldin et al. 2000, Menzel et al. 2000a,b). The results, however, were disappointing, because the staining times required were too long ( $24 \mathrm{~h})$ and the working solutions were too unstable. More recent studies have provided only limited improvements (Yu-Juan et al. 2008). The combination of QDs and dendrimers does not seem to constitute an alternative to the existing cyanoacrylate stains.

In another recent study, researchers stabilized QDs in petroleum ether by grafting aliphatic chains on their outer surface and attempted to detect sebaceous fingermarks with these nanomaterials. Promising results were obtained on silicon wafers, but on porous surfaces, the results were limited due to high background luminescence (Sametband et al. 2007).

Cadmium sulfide (CdS) encapsulated in a biopolymeric chitosan matrix has been used as dusting powder for detecting fresh marks on aluminium foil (Dilag et al. 2009).

Luminescent fingermarks were obtained, but the process involved in the detection is only physical. Moreover, the use of dried cadmium-based nanoparticles as dusting powder has serious health and safety implications. Water soluble cadmium selenide (CdSe) QDs have been synthesized and used to detect fresh marks on the adhesive surface of tape with promising results (Wang et al. 2009). Cadmium telluride (CdTe) QDs, synthesized in aqueous solution, were used to detect blood fingermarks on various nonporous surfaces (Becue et al. 2009) such as aluminium foil, black polyethylene, glass or transparent polypropylene (Fig. 16). A comparison with acid yellow 7 , one of the best blood reagents for nonporous substrates 


\section{Silica nanoparticles}

Synthesis of silica nanoparticles is simple and consists of a succession of hydrolysis/condensation processes on silicon alkoxide precursors $\left(\mathrm{Si}-(\mathrm{O}-\mathrm{R})_{4} ; \mathrm{R}=\right.$ an alkyl chain). This leads to the formation of silicon oxide nanoparticles in suspension in water (Stöber and Fink 1968) or in a water-in-oil emulsion (Arriagada and Osseo-Asare 1999, Bagwe et al. 2004). The introduction of organic dyes during the synthesis permits their attachment to the nanoparticle surface or to their embedment within the particles (van Blaaderen and Vrij 1992, Santra et al. 2001, Tapec et al. 2002, Zhao et al. 2004, Johnston et al. 2005). Such dye-doped nanoparticles currently are widely used as labeling agents for bioimaging purposes. They are highly efficient alternatives to classical organic fluorophores, because the silica coating (or encapsulation) of some dyes isolates them from the oxygen and water of the outside environment. This both increases photostability and emission quantum yield of the dye and decreases photobleaching by preventing penetration of oxygen, which promotes photodecomposition (Tan et al. 2004).

In the context of fingermark detection, the use of luminescent silica nanoparticles for forensic purposes remains at the pilot study stage. Theaker et al. (2008) recently reported entrapment of a variety of colored and fluorescent dyes including basic red 28, basic yellow 
40, fluorescein, methylene blue, oxazine perchlorate, rhodamine $\mathrm{B}$, rhodamine $6 \mathrm{G}$ and thiazole orange within silica particles. The resulting doped nanoparticles were used in aqueous suspensions to detect fingerprints. The process is very similar to that described for small particle reagents. Micron-size particles also were used as dusting agents. Both fresh (20 min) and aged fingermarks (40 days old) showed good definition after development.

Current research projects in our laboratory aim to use dye-doped silica nanoparticles that are functionalized chemically to recognize the fingermark residue. Such dye-doped nanoparticles can be considered inert labeling agents that require appropriate functionalization to promote (bio)molecular interactions or reactions with components of interest. One advantage of the silica nanoparticles is the versatility provided by their surfaces for chemical modification. This is because the surfaces of silica nanoparticles carry silanol groups ( $\mathrm{Si}-\mathrm{OH})$. These moieties readily undergo chemical modifications, such as the addition of an additional siloxane layer using an organosilane or functionalized alkoxysilane, e.g., $\mathrm{X}-\left(\mathrm{CH}_{2}\right)_{\mathrm{m}}-\mathrm{Si}-(\mathrm{OR})_{3}$; where $\mathrm{X}$ is the functionality to be added. Other chemical modifications include addition of alkyl chains bearing amine, carboxyl, or thiol functionalities (Fig. 17). The incorporation of chemical groups onto the silica surface allows tailoring of the chemical behavior of the surface, and thus the nanoparticle as a whole, compared to inert "naked" particles. The challenge in forensic science is to find the best functionalities to add to dye-doped silica nanoparticles to enhance targeting of latent fingermarks on a wide range of substrates. Preliminary results are encouraging and suggest the considerable potential of such a strategy for detecting fingermarks by combining the intense luminescence of the dye-doped silica nanoparticles and the selectivity of the grafted ligands.

In forensic science, and more particularly in the context of fingermark detection, stains play a key role. To cover the subject as completely as possible, we chose to define a "stain" as every chemical entity (organic molecule, metal nanoparticle, dye-doped nano- and micro- 
structured element, or other compound) that can create a contrast between a latent fingermark and its underlying substrate. This wide definition goes beyond the conventional organic dyes or organic dye-doped nanoparticles that currently are used for bio-imaging applications, because it also encompasses entities such as iodine, metal salts, or metal nano- or microparticles, which are excellent contrast elements.

With this review, we aimed at presenting various aspects of fingermark detection using dyes. The possibilities offered to forensic scientists are numerous and include conventional staining of the lipid fraction of fingermarks, chemical targeting of amino acids or proteins, selective polymerization on the secretion residue, or the use of more complex physico-chemical processes. The choice for one technique over another, or for a combination of different ones, is determined mainly by the nature of the item or by the surface at the crime scene, e.g., walls or furniture, and by the context of the criminal affair, e.g., timeline, bloody case, evidence exposed to environmental elements, prolonged exposure to water. In addition, the choice for a luminescent dye or a conventional stain is strongly dependant on the nature and color of the substrate, even if it is generally recognized that luminescent techniques are more sensitive compared to nonluminescent ones.

During the last decade, several investigations have focused on the development of new detection techniques based on the use of functionalized and/or luminescent nanoparticles for detecting fingermarks. Nanoparticles have great promise for fingermark detection due to their high surface-to-volume ratio, their size-dependent qualities, their optical properties and the fact that they can easily be tuned chemically. If surface modification and composition control are combined, these properties impart high selectivity and sensitivity. The results currently are promising and could provide forensic scientists with new and efficient alternatives to the currently existing techniques. 


\section{Acknowledgment}

The authors thank the Swiss National Science Foundation (SNF) for supporting the research in the field of new fingermark detection reagents based on luminescent nanoparticles (Ambizione grant no. PZ00P2_121907/1). 


\title{
References
}

Adcock JM (1977) The development of latent fingerprints on human skin: the silver plate method. J. Forensic Sci. 22: 599-605.

Allman DS, Pounds CA (1991) Diaminobenzidine: a simple, safe and sensitive method for the enhancement of blood marks at scene of crime and in the laboratory. Central Research and Support Establishment. Aldermaston, UK Home Office Forensic Science Service.

Allman DS, Pounds CA (1992) The specificity of diaminobenzidine for the detection of blood. Home Office Forensic Science Service. Aldermaston, UK, Central Research and Support Establishment.

Almog J (2001) Fingerprint development by ninhydrin and its analogues. In: Lee HC, Gaensslen RE., Eds. Advances in Fingerprint Technology, 2nd ed. CRC Press, Boca Raton, FL. pp. 177-209.

Almog J, Hirshfeld A, Klug JT (1982) Reagents for the chemical development of latent fingerprints: synthesis and properties of some ninhydrin analogues. J. Forensic Sci. 27: 912917.

Almog J, Hirshfeld A, Franck A, Grant Z, Ittah Y (1992) 5-Methylthio-ninhydrin and related compounds: a novel class of fluorogenic fingerprint reagents. J. Forensic Sci. 37: 688694.

\begin{abstract}
Almog J, Sears VG, Springer E, Hewlett DF, Walker S, Wiesner S, Lidor R, Bahar E (2000) Reagents for the chemical development of latent fingerprints: scope and limitations of benzo[f]ninhydrin in comparison to ninhydrin. J. Forensic Sci. 45: 538-544.
\end{abstract}

Almog J, Cohen Y, Azoury M, Hahn T-R (2004) Genipin, a novel fingerprint reagent with colorimetric and fluorogenic activity. J. Forensic Sci. 49: 255-257.

Angst E (1962) Procédés pour la détermination de l'âge d'empreintes dactyloscopiques sur le papier. RICPTS 16: 134-146.

Arndt CB (1985) Iodine silver plate transfer method. RCMP Gazette 47: 19-21.

Arriagada FJ, Osseo-Asare K (1999) Controlled hydrolysis of tetraethoxysilane in a nonionic water-in-oil microemulsion: a statistical model of silica nucleation. Coll. Sur. A 154: 311-326. 
Aubert P (1877-1878) Des modifications subies par la sécrétion de la sueur dans les maladies de la peau. Ann. Derm. Syphiligraph. 9: 359-373.

Bagwe RP, Zhao X, Tan W (2003) Bioconjugated luminescent nanoparticles for biological applications. J. Disper. Sci. Technol. 24: 453-464.

Bagwe RP, Yang C, Hilliard LR, Tan W (2004) Optimization of dye-doped silica nanoparticles prepared using a reverse microemulsion method. Langmuir 20: 8336-8342.

Bawendi MG, Steigerwald ML, Brus LE (1990) The quantum mechanics of larger semiconductor clusters ("quantum dots"). Ann. Rev. Phys. Chem. 41: 477-496.

Beaudoin A (2004) New technique for revealing latent fingerprints on wet, porous surfaces: oil red O. J. Forensic Ident. 54: 413-420.

Becue A, Scoundrianos A, Champod C, Margot P (2008) Fingermark detection based on the in situ growth of luminescent nanoparticles - towards a new generation of multimetal deposition. Forensic Sci. Internat. 179: 39-43.

Becue A, Moret S, Champod C, Margot PA (2009) Use of quantum dots in aqueous solution to detect blood fingermarks on nonporous surfaces. Forensic Sci. Internat. 191: 3641.

Bergeron J (2003) Development of bloody prints on dark surfaces with titanium dioxide and methanol. J. Forensic Ident. 53: 149-161.

Bicknell DE, Ramotowski RS (2008) Use of an optimized 1,2-indanedione process for the development of latent prints. J. Forensic Sci. 53: 1108-1116.

Blackledge RD (1998) Re: "latent print processing by the ruthenium tetroxide method" [letter plus editor's reply]. J. Forensic Ident. 48: 557-559.

Bouldin KK, Menzel RE, Takatsu M, Murdock RH (2000) Diimide-enhanced fingerprint detection with photoluminescent CdS/dendrimer nanocomposite. J. Forensic Sci. 45: 12391242.

Brennan J, Bramble S, Crabtree S, Wrignt G (1995) Fuming of latent fingerprints using dimethylaminocinnamaldehyde. J. Forensic Ident. 45: 373-380.

Bruchez M, Moronne M, Gin P, Weiss S, Alivisatos AP (1998) Semiconductor nanocrystals as fluorescent biological labels. Science 281: 2013-2016. 
Bukowski TJ, Simmons JH (2002) Quantum dot research: current state and future prospects. Crit. Rev. Solid State 27: 119-142.

Caldwell JP, Henderson W, Kim ND (2000) ABTS: A safe alternative to DAB for the enhancement of blood fingerprints. J. Forensic Sci. 45: 785-794.

Cantu AA (2001) Silver physical developers for the visualization of latent prints on paper. Forensic Sci. Rev. 13: 32-64.

Cantu AA, Johnson JL (2001) Silver physical development of latent prints. In: Lee HC, Gaensslen RE, Eds. Advances in Fingerprint Technology, $2^{\text {nd }}$ ed. CRC Press, Boca Raton, FL. pp. 242-247, 254.

Champod C, Lennard C, Margot P, Stoilovic M (2004) Fingerprints and Other Ridge Skin Impressions. CRC Press LLC, Boca Raton, FL.

Cheeseman R, DiMeo LA (1995) Fluorescein as a field-worthy latent bloodstain detection system. J. Forensic Ident. 45: 631-646.

\section{Choi MJ, McDonagh AM, Maynard PJ, Wuhrer R, Lennard C, Roux C (2006)}

Preparation and evaluation of metal nanopowders for the detection of fingermarks on nonporous surfaces. J. Forensic Ident. 56: 756-768.

\section{Choi MJ, Smoother T, Martin AA, McDonagh AM, Maynard PJ, Lennard C, Roux C} (2007) Fluorescent $\mathrm{TiO}_{2}$ powders prepared using a new perylene diimide dye: Applications in latent fingermark detection. Forensic Sci. Int. 173: 154-160.

\section{Choi MJ, McBean KE, Ng PHR, McDonagh AM, Maynard PJ, Lennard C, Roux C} (2008a) An evaluation of nanostructured zinc oxide as a fluorescent powder for fingerprint detection. J. Mater. Sci. 43: 732-737.

Choi MJ, McDonagh AM, Maynard P, Roux C (2008b) Metal-containing nanoparticles and nano-structured particles in fingermark detection. Forensic Sci. Int. 179: 87-97.

Coulier M (1863) Les vapeurs d'iode employées comme moyen de reconnaître l'altération des écritures. In: Figuier L, Ed. L'année Scientifique et Industrielle - Huitième Année. Hachette, Paris. pp. 157-160.

Cucè P, Polimeni G, Lazzaro AP, De Fulvio G (2004) Small particle reagents technique can help to point out wet latent fingerprints. Forensic Sci. Int. 146S: S7-S8. 
Dalrymple BE, Duff JM, Menzel ER (1977) Inherent fingerprint luminescence — detection by laser. J. Forensic Sci. 22: 106-115.

Day KJ, Bowker W (1996) Enhancement of cyanoacrylate developed latent prints using Nile red. J. Forensic Ident. 46: 183-187.

Dilag J, Kobus H, Ellis AV (2009) Cadmium sulfide quantum dot/chitosan nanocomposites for latent fingermark detection. Forensic Sci. Int. 187: 97-102.

Drapel V, Becue A, Champod C, Margot P (2009) Identification of promising antigenic components in latent fingermark residues. Forensic Sci. Int. 184: 47-53.

Durussel P, Stauffer E, Becue A, Champod C, Margot P (2009) Single-metal deposition: Optimization of this fingermark enhancement technique. J. Forensic Ident. 59: 80-96.

Frank A, Almog J (1993) Modified SPR for latent fingerprint development on wet, dark objects. J. Forensic Ident. 43: 240-244.

Frens G (1973) Controlled nucleation for the regulation of the particle size in monodisperse gold suspensions. Nat. Phys. Sci. 241: 20-22.

Gardner SJ, Hewlett DF (2003) Optimization and initial evaluation of 1,2-indandione as a reagent for fingerprint detection. J. Forensic Sci. 48: 1288-1292.

Goode GC, Morris JR (1983) Latent fingerprints: a review of their origin, composition and methods for detection. Atomic Weapons Research Establishment Report no. 022/83, Aldermaston, UK.

Gray C (1978) The detection and persistence of latent fingerprints on human skin: an assessment of the iodine-silver plate method. J. Forensic Sci. Soc. 18: 47-52.

Grigg R, Malone JF, Mongkolaussavaratana T, Thianpatanagul S (1986) Cycloaddition reactions relevant to the mechanism of the ninhydrin reaction: X-ray crystal structure of protonated Ruhemann's purple, a stable 1,3-dipole. J. Chem. Soc. Chem. Commun. 421-422.

Grigg R, Mongkolaussavaratana T, Pounds CA, Sivagnanam S (1990) 1,8diazafluorenone and related compounds - a new reagent for the detection of alpha amino acids and latent fingerprints. Tetrahedron Lett. 31: 7215-7218.

Grzegorzewska E, Filbrandt B (2004) Enhancement of latent fingermarks with RTX method. Prob. Kryminal. 246: 19-24. 
Guigui K, Beaudoin A (2007) The use of oil red O in sequence with other methods of fingerprint development. J. Forensic Ident. 57: 550-581.

Hansen DB and Joullié MM (2005) The development of novel ninhydrin analogues. Chem. Soc. Rev. 34: 408-417.

Haque F, Westland A, Kerr FM (1983) An improved non-destructive method for detection of latent fingerprints on documents with iodine-7,8-benzoflavone. Forensic Sci. Int. 21: 7983.

Hart A (2003) The detection and development of fingerprints with lipid dyes, $5^{\text {th }}$ International Fingerprint Research Group Meeting. St. Albans, UK.

Home Office Scientific Development Branch (2005) Solvent black 3 for scenes of crime. HOSDB Fingerprint Development and Imaging Newsletter Publication No.20/05: 2-3.

Home Office Scientific Development Branch (2006) Use of DMAC on thermal papers. HOSDB Fingerprint and Footwear Forensics Newsletter Publication No.58/06: 2-4.

Horobin RW (1988) Understanding Histochemistry: Selection, Evaluation and Design of Biological Stains. Ellis Horwood, Chichester, England.

Hughes JG (1993) Under the COSHH. Fingerprint Whorld 19.

Hussain JI, Pounds CA (1988) The enhancement of marks in blood, part 1, 5sulphosalicylic acid: a convenient and effective fixative for marks made in blood. Technical CRSE Aldermaston, UK, Central Research and Support Establishment. No. 649.

James JD, Pounds CA, Wilshire B (1991a) Flake metal powders for revealing latent fingerprint. J. Forensic Sci. 36: 1368-1375.

James JD, Pounds CA, Wilshire B (1991b) Magnetic flake fingerprint technology. J. Forensic Ident. 41: 237-247.

James JD, Pounds CA, Wilshire B (1992) New magnetic applicators and magnetic flake powders for revealing latent fingerprints. J. Forensic Ident. 42: 531-542.

James JD, Pounds CA, Wilshire B (1993) Magnetic flake powders for fingerprint development. J. Forensic Sci. 38: 391-401.

Jasuja OP, Singh GD, Sodhi GS (2008) Small particle reagents: development of fluorescent variants. Sci. Just. 48: 141-145. 
Jelly R, Lewis SW, Lennard C, Lim KF, Almog J (2008) Lawsone: a novel reagent for the detection of latent fingermarks on paper surfaces. Chem. Commun. 30: 3513-3515.

Johnston APR, Battersby BJ, Lawrie GA, Trau M (2005) Porous functionalised silica particles: a potential platform for biomolecular screening. Chem. Commun. 7: 848-850.

Joullié MM, Thompson TR, Nemeroff NH (1991) Ninhydrin and ninhydrin analogs: synthesis and applications. Tetrahedron Lett. 47: 8791-8830.

Joullié MM, Ramotowski RS, Cantu AA (1998) 1,2-Indanediones: new reagents for visualizing the amino acid components of latent prints. J. Forensic Sci. 43: 744-747.

Kasper SP, Minnillo DJ, Rockhold AM (2002) Validating ind (1,2-indanedione). Forensic Sci. Comm. 4: 4.

Kaur J (2006) Novel fluorescent fingerprint dusting compositions. Fingerprint Whorld 33: 20-24.

Kobus HJ, Stoilovic M, Warrener RN (1983) Simple luminescent post-ninhydrin treatment for the improved visualisation of fingerprints on documents in cases where ninhydrin alone gives poor results. Forensic Sci. Int. 22: 161-170.

Królikowska A, Bukowska J (2007) Self-assembled monolayers of mercaptosuccinic acid on silver and gold surfaces designed for protein binding. Part I. Structure of the monolayer. $J$. Raman Spectros. 38: 936-942.

Lamothe PJ, McCormick PG (1972) Influence of acidity on the reaction of ninhydrin with amino acids. Anal. Chem. 44: 821-825.

Lee HC (1984) Benzidine or o-tolidine. Identification News 34: 13-14.

Lee HC, Gaensslen RE (1984) Cyanoacrylate fuming - theory and procedures. Identification News 34: 8-14.

Lee HC, Gaensslen RE (2001) Methods of latent fingerprint development. In: Lee HC, Gaensslen RE, Eds. Advances in Fingerprint Technology, $2^{\text {nd }}$ ed. CRC Press, Boca Raton, FL. pp. 216-276.

Lee S-W, Lim J-M, Bhoo S-H, Paik Y-S, Hahn T-R (2003) Colorimetric determination of amino acids using genipin from gardenia jasminoides. Anal. Chim. Acta 480: 267-274. 
Leggett R, Lee-Smith EE, Jickells SM, Russell DA (2007) “Intelligent” fingerprinting: simultaneous identification of drug metabolites and individuals by using antibodyfunctionalized nanoparticles. Angew. Chem. Int. Ed. 46: 4100-4103.

Lennard CJ, Margot PA, Stoilovic M, Warrener RN (1986) Synthesis of ninhydrin analogues and their application to fingerprint development: preliminary results. J. Forensic Sci. Soc. 26: 323-328.

Lennard CJ, Margot PA, Sterns M, Warrener RN (1987) Photoluminescent enhancement of ninhydrin developed fingerprints by metal complexations: structural studies of complexes formed between Ruhemann's purple and group IIb metal salts. J. Forensic Sci. 32: 597-605. Lennard CJ, Margot PA, Stoilovic M, Warrener RN (1988) Synthesis and evaluation of ninhydrin analogues as reagents for the development of latent fingerprints on paper surfaces. J. Forensic Sci. Soc. 28: 3-23.

Levinton-Shamuilov G, Cohen Y, Azoury M, Chaikovsky A, Almog J (2005) Genipin, a novel fingerprint reagent with colorimetric and fluorogenic activity. Part II: Optimization, scope and limitations. J. Forensic Sci. 50: 1367-1371.

\section{Lewis LA, Smithwick RWI, Devault GL, Bolinger B, Lewis SAS (2001) Processes} involved in the development of latent fingerprints using the cyanoacrylate fuming method. $J$. Forensic Sci. 46: 241-246.

Lock ERA, Mazzella WD, Margot PA (1995) A new europium chelate as a fluorescent dye for cyanoacrylate pretreated fingerprints - EuTTAPhen: europium thenoyltrifluoro-acetone ortho-phenanthroline. J. Forensic Sci. 40: 354-358.

Mankidy PJ, Rajagopalan R, Foley HC (2006) Facile catalytic growth of cyanoacrylate nanofibers. Chem. Commun.: 1139-1141.

Marchant B, Tague C (2007) Developing fingerprints in blood: a comparison of several chemical techniques. J. Forensic Ident. 57: 76-93.

Mashito K, Makoto I (1977) Latent fingerprint processing: iodine 7,8 benzoflavone method. Identification News 27: 3.

Mashiko K, Miyamoto T (1998) Latent fingerprint processing by the ruthenium tetroxide. $J$. Forensic Ident. 48: 279-290. 
Mashiko K, German ER, Motojima K, Colman CD (1991) RTX: a new ruthenium tetroxide fuming procedure. J. Forensic Ident. 41: 429-436.

Mazzella WD, Lennard C (1995) An additional study of cyanoacrylate stains. J. Forensic Ident. 45: 5-18.

McCarthy MM (1990) Evaluation of Ardrox as a luminescent stain for cyanoacrylate processed latent impressions. J. Forensic Ident. 40: 75-80.

McComiskey P (1990) DFO: a simple and quick method for the development of latent fingerprints. Fingerprint Whorld 16: 64-65.

Medintz IL, Uyeda HT, Goldman ER, Mattoussi H (2005) Quantum dot bioconjugates for imaging, labelling and sensing. Nat. Mater. 4: 435-446.

Menzel ER (1999) Fingerprint Detection with Lasers, $2^{\text {nd }}$ ed. Marcel Dekker, Inc., New York.

Menzel RE, Savoy SM, J. US, Cheng KH, Murdock RH, Sudduth MR (2000a)

Photoluminescence semiconductor nanocrystals for fingerprint detection. J. Forensic Sci. 45: 545-551.

Menzel RE, Takatsu M, Murdock RH, Bouldin K, Cheng KH (2000b) Photoluminescent CdS / dendrimer nanocomposites for fingerprint detection. J. Forensic Sci. 45: 770-773.

Michalet X, Pinaud FF, Bentolila LA, Tsay JM, Doose S, Li JJ, Sundaresan G, Wu AM, Gambhir SS, Weiss S (2005) Quantum dots for live cells, in vivo imaging, and diagnostics. Science 307: 538-544.

Murcia MJ, Naumann CA (2005) Biofunctionalization of fluorescent nanoparticles. In: Kumar CSSR, Ed. Biofunctionalization of Nanomaterials. Wiley-VCH Verlag GmbH \& Co. KGaA, Weinheim, Germany. pp. 1-40.

Murray CB, Norris DJ, Bawendi MG (1993) Synthesis and characterization of nearly monodisperse $\mathrm{CdE}(\mathrm{E}=\mathrm{S}, \mathrm{Se}, \mathrm{Te})$ semiconductor nanocrystallites. J. Am. Chem. Soc. 115: 8706-8715.

Navarro E, Castelló A, López-Alfaro JA, Verdú F (2006) Criminalistic: effectiveness of lysochromes on the developing of invisible lipstick-contaminated lipmarks on human skin: a preliminary study. Forensic Sci. Int. 158: 9-13. 
Nygren H, Tengvall P, Lundström I (1997) The initial reactions of $\mathrm{TiO}_{2}$ with blood. $J$.

Biomed. Mater. Res. A 34: 487-492.

Odén S,Von Hofsten B (1954) Detection of fingerprints by the ninhydrin reaction. Nature 173: 449-450.

Olenik JH (1992) Ardrox: an alternate solvent system. J. Forensic Ident. 42: 513-516.

Olenik JH (1997) A simple three dye blend. J. Forensic Ident. 47: 530-533.

Olsen RD (1978) Scott's Fingerprint Mechanics, Springfield, IL.

Petraco NDK, Proni G, Jackiw JJ, Sapse A-M (2006) Amino acid alanine reactivity with the fingerprint reagent ninhydrin. A detailed ab initio computational study. J. Forensic Sci. 51: 1267-1275.

Pfister R (1985) The optical revelation of latent fingerprints. Fingerprint Whorld 10: 64-70.

Pounds CA, Griggs R, Mongkolaussavaratana T (1990) The use of 1,8-diazafluoren- 9-one (DFO) for the fluorescent detection of latent fingerprints on paper: a preliminary evaluation. J. Forensic Sci. 35: 169-175.

Ramotowski RS (1996) Fluorescence visualization of latent fingerprints on paper using pdimethylaminocinnamaldehyde (pDMAC). Proceedings of the International Symposium on Fingerprint Detection and Identification, Ne'urim, Israel.

Ramotowski RS (2001) Composition of latent print residue. In: Lee HC, Gaensslen RE, Eds. Advances in Fingerprint Technology, 2nd ed. CRC Press, Boca Raton, FL. pp. 63-104.

Rawji A, Beaudoin A (2006) Oil red O versus physical developer on wet papers: a comparative study. J. Forensic. Ident. 56: 33-54.

Reiss RA (1903) La photographie Judiciaire. C. Mendel, Paris. Reiss RA (1911) Manuel de Police Scientifique (Technique) - I. Vols et Homicides. Felix Alcan, Paris.

Resch-Genger U, Grabolle M, Cavaliere-Jaricot S, Nitschke R, Nann T (2008) Quantum dots versus organic dyes as fluorescent labels. Nat. Methods 5: 763-775.

Roux C, Jones N, Lennard C, Stoilovic M (2000) Evaluation of 1,2-indanedione and 5,6dimethoxy-1,2-indanedione for the detection of latent fingerprints on porous surfaces. $J$. Forensic Sci. 45: 761-769. 
Russell S, John G, Naccarato S (2008) Modifications to the 1,2-indanedione/zinc chloride formula for latent print development. J. Forensic Ident. 58: 182-192.

Saferstein R, Graf SL (2001) Evaluation of a reflected ultraviolet imaging system for fingerprint detection. J. Forensic Ident. 51: 385-393.

Sahs PT (1992) DAB: an advancement in blood print detection. J. Forensic Ident. 42: 412420.

Saitoh N, Akiba N (2005) Ultraviolet fluorescence spectra of fingerprints. Sci. World J. 5: 355-366.

Saitoh N, Akiba N (2006) Ultraviolet fluorescence imaging of fingerprints. Sci. World J. 6: 691-699.

Sametband M, Shweky I, Banin U, Mandler D, Almog J (2007) Application of nanoparticles for the enhancement of latent fingerprints. Chem. Commun. [Q13]: 1142-1144.

Santra S, Wang K, Tapec R, Tan W (2001) Development of novel dye-doped silica nanoparticles for biomarker application. J. Biomed. Opt. 6: 160-166.

Sasson Y, Almog J (1978) Chemical reagents for the development of latent fingerprints, 1. Scope and limitations of the reagent 4-dimethylaminocinnamaldehyde. J. Forensic Sci. 23: 852-855.

Saunders G (1989) Multimetal deposition method for latent fingerprint development. 74th Annual Educational Conference of the International Association for Identification, Pensacola, FL.

Schnetz B, Margot P (2001) Technical note: latent fingermarks, colloidal gold and multimetal deposition (MMD) - optimisation of the method. Forensic Sci. Int. 118: 21-28.

Sears VG, Prizeman TM (2000) Enhancement of fingerprints in blood - part 1. The optimization of amido black. J. Forensic Ident. 50: 470-480.

Sears VG, Butcher CPG, Prizeman TM (2001) Enhancement of fingerprints in blood - part 2. Protein dyes. J. Forensic Ident. 51: 28-38.

Sears VG, Butcher CPG, Fitzgerald LA (2005) Enhancement of fingerprints in blood - part 3. Reactive techniques, acid yellow 7, and process sequences. J. Forensic Ident. 55: 741-763.

Slot JW, Geuze HJ (1981) Sizing of protein A-colloidal gold probes for immunoelectron microscopy. J. Cell Biol. 90: 533-536. 
Sodhi GS, Kaur J (2001) Powder method for detecting latent fingerprints: a review. Forensic Sci. Int. 120: 172-176.

Sodhi GS, Kaur J (2004) A fingerprint powder formulation involving cyano blue dye. Fingerprint Whorld 30: 163.

Sodhi GS, Kaur J (2005) Proflavin-based fingerprint dusting composition. Fingerprint Whorld 31: 239.

Spindler X, Stoilovic M, Lennard C, Lennard A (2009) Spectral variations for reaction products formed between different amino acids and latent fingermark detection reagents on a range of cellulose-based substrates. J. Forensic. Ident. 59: 308-324.

Springer E, Bergman P (1995) A fluorescent small particle reagent (SPR). J. Forensic Ident. 45: 164-168.

Springer E, Almog J, Frank A, Ziv Z, Bergman P, Gui Qiang W (1994) Detection of dry body fluids by inherent short wavelength UV luminescence. Forensic Sci. Int. 66: 164-168.

Stauffer E, Becue A, Singh KV, Thampi KR, Champod C, Margot P (2007) Single-metal deposition (SMD) as a latent fingermark enhancement technique: an alternative to multimetal deposition (MMD). Forensic Sci. Int. 168: e5-e9.

Stöber W, Fink A (1968) Controlled growth of monodisperse silica spheres in the micron size range. J. Coll. Interf. Sci. 26: 62-69.

Stoilovic M (1991) Detection of semen and blood stains using Polilight as a light source. Forensic Sci. Int. 51: 289-296.

Stoilovic M, Kobus HJ, Margot PA, Warrener RN (1986) Improved enhancement of ninhydrin developed fingerprints by cadmium complexation using low temperature photoluminescence techniques. J. Forensic Sci. 31: 432-445.

Stoilovic M, Lennard C, Wallace-Kunkel C, Roux C (2007) Evaluation of a 1,2indanedione formulation containing zinc chloride for improved fingermark detection on paper. J. Forensic Ident. 57: 4-18.

Sturelle V, Cominotti C, Henrot D, Desbrosse X (2006) The use of camphor in the development of latent prints on unfired cartridge casings. J. Forensic Ident. 56: 694-705.

Tan W, Wang K, He X, Zhao XJ, Drake T, Wang L, Bagwe RP (2004)

Bionanotechnology based on silica nanoparticles. Med. Res. Rev. 24: 621-638. 
Tapec R, Zhao XJ, Tan W (2002) Development of organic dye-doped silica nanoparticles for bioanalysis and biosensors. J. Nanosci. Nanotechnol. 2: 405-409.

Theaker BJ, Hudson KE, Rowell FJ (2008) Doped hydrophobic silica nano- and microparticles as novel agents for developing latent fingerprints. Forensic Sci. Int. 174: 26-34.

Thomas GL (1973) The physics of fingerprints. Criminology 8: 21-38.

Thomas GL (1975) The resistivity of fingerprints. J. Forensic Sci. Soc. 15: 133-135.

Thurn KT, Brown EMB, Wu A, Vogt S, Lai B, Maser J, Paunesku T, Woloschak GE (2007) Nanoparticles for applications in cellular imaging. Nanoscale Res. Lett. 2: 430-441. Topoglidis E, Campbell CJ, Cass AEG, Durrant J, R. (2001) Factors that affect protein adsorption on nanostructured titania films. A novel spectroelectrochemical application to sensing. Langmuir 17: 7899-7906.

Turkevich J (1985a) Colloidal gold - part I. Gold Bull. 18: 86-91.

Turkevich J (1985b) Colloidal gold - part II. Gold Bull. 18: 125-131.

Turkevich J, Stevenson PC, Hillier J (1951) A study of the nucleation and growth process in the synthesis of colloidal gold. Disc. Faraday Soc. 11: 55-75.

van Blaaderen A, Vrij A (1992) Synthesis and characterization of colloidal dispersions of fluorescent, monodisperse silica spheres. Langmuir 8: 2921-2931.

Voss-de Haan P (2006) Physics and fingerprints. Contemp. Phys. 47: 209-230.

Waldoch TL (1993) The flame method of soot deposition for the development of latent prints on nonporous surfaces. J. Forensic Ident. 43: 463-465.

Wallace-Kunkel C, Lennard C, Stoilovic M, Roux C (2007) Optimisation and evaluation of 1,2-indanedione for use as a fingermark reagent and its application to real samples. Forensic Sci. Int. 168: 14-26.

Wang Y, Herron N (1991) Nanometer-sized semiconductor clusters: materials synthesis, quantum size effects, and photophysical properties. J. Phys. Chem. 95: 525-532.

Wang Y, Weiping Z, Janping M (2007) Eosin Y detection of latent blood prints. J. Forensic Ident. 57: 54-58. 
Wang YF, Yang RQ, Wang YJ, Shi ZX, Liu JJ (2009) Application of CdSe nanoparticle suspension for developing latent fingermarks on the sticky side of adhesives. Forensic Sci. Int. 185: 96-99.

Wargacki SP, Lewis LA, Dadmun MD (2007) Understanding the chemistry of the development of latent fingerprints by superglue fuming. J. Forensic Sci. 52: 1057-1062.

Webb JL, Creamer JI, Quickenden TI (2006) A comparison of the presumptive luminol test for blood with four non-chemiluminescent forensic techniques. Luminescence 21: 214220.

Wiesner S, Springer E, Sasson Y, Almog J (2001) Chemical development of latent fingerprints: 1,2-indanedione has come of age. J. Forensic Sci. 46: 1082-1084.

Wilkinson D (2000a) Spectroscopic study of 1,2-indanedione. Forensic Sci. Int. 114: 123132.

Wilkinson D (2000b) Study of the reaction mechanism of 1,8-diazafluoren-9-one with the amino acid L-alanine. Forensic Sci. Int. 109: 87-103.

Williams NH, Elliot KT (2005) Development of latent prints using titanium dioxide $\left(\mathrm{TiO}_{2}\right)$ in small particle reagent, white (SPR-w) on adhesives. J. Forensic Ident. 55: 292-301.

Yapping L, Yue W (2004) Bloody latent fingerprint detection using LeuR6G. J. Forensic Ident. 54: 542-546.

\section{Yu-Juan J, Yun-Jun L, Guo-Ping L, Jie L, Yuan-Feng W, Rui-Qin Y, Wen-Ting L} (2008) Application of photoluminescent CdS/PAMAM nanocomposites in fingerprint detection. Forensic Sci. Int. 179: 34-38.

Zhao X, Bagwe RP, Tan W (2004) Development of organic-dye-doped silica nanoparticles in a reverse microemulsion. Adv. Mater. 16: 173-176.

Ziv Z, Springer E (1993) More applications of coaxial illumination in fingerprint detecting and photography. J. Forensic Ident. 43: 362-367.

Zollinger H (2003) Color chemistry: Syntheses, Properties, and Applications of Organic Dyes and Pigments, $3^{\text {rd }}$ ed. VHCA, Zurich and Wiley-VHC, Weinheim. 
Fig. 1. Left: molecular structure of oil red O. Right: representative fingermark detected using this technique with paper as substrate.

Fig. 2. Polymerization mechanism on the secretion residue during the cyanoacrylate fuming process.

Fig. 3. Left: cyanoacrylate-fumed fingermark located on a beer glass. Note that the quality of development is not optimal. Right: same fingermark after enhancement using rhodamine 6G as a cyanoacrylate dye and observed using luminescence.

Fig. 4. Chart illustrating the excitation and emission wavelength ranges for the most commonly used cyanoacrylate dyes, the colors of which are indicated on the diagram. Abbreviations: BY40, basic yellow 40; BR28 basic red 28; S7 Styryl 7.

Fig. 5. Reaction mechanism between ninhydrin and amino acid leading to the formation of a dark purple product, Ruhemann's purple.

Fig. 6. Left: molecular structure of ninhydrin (2,2-dihydroxy-1,3-indanedione). Right: representative fingermark detected using this technique with paper as substrate.

Fig. 7. Left: molecular structure of 1,2-indanedione. Right: representative fingermark detected using this technique with paper as substrate and observed using luminescence. 
Fig. 8. Left: molecular representation of acid yellow 7. Right: representative blood fingermark detected using this technique with aluminium foil as substrate.

Fig. 9. Schematic illustration of the main characteristics of nanoparticles influencing their use as fingermark detection reagents. Good contrast is obtained when the ridges of the mark are targeted specifically, but not the underlying substrate.

Fig. 10. Schematic illustration of the functionalization strategy involving addition of ligands on the outer surface of nanoparticles to increase affinity for the secretion residue.

Fig. 11. Schematic illustration of the two-step metal deposition application protocols. This chart shows MMD, SMD, and $\mathrm{MMD}_{\text {lumin, }}$ which differ in terms of which metal is used for enhancement, silver, gold, and zinc, respectively.

Fig. 12. Schematic representation of the differences among the three metal deposition protocols in terms of final nanoparticle composition and detected fingermarks. MMD and SMD produce dark colored fingermarks, whereas luminescent $\mathrm{MMD}\left(\mathrm{MMD}_{\text {lumin }}\right)$ generates luminescent fingermarks.

Fig. 13. Schematic illustration of the two processes involved in the physical developer detection technique in terms of the distance between the secretion residue and the site of colloid formation. Top: in solution. Bottom: close to the residue.

Fig. 14. Left: schematic representation of the oleylamine-functionalized gold nanoparticle used as nanopowder dusting on fingermarks (Choi et al. 2006). Right: schematic 
representation of the alkanethiol-capped gold nanoparticle (Au-NP-C18) used to detect sebaceous fingermarks on porous and nonporous surfaces in an enhanced physical developer process (Sametband et al. 2007).

Fig. 15. Schematic representation of the "protein A/antibody"-functionalized gold nanoparticle used to detect fingermarks by antibody/antigen recognition. The illustrated fingermark was obtained from a male smoker after 40 min sweating and detected using the anti-cotinine-functionalized nanoparticles with Alexa Fluor 546 as luminescent marker. Fingermark reproduced with permission from (Leggett et al. 2007), Copyright Wiley-VCH Verlag GmbH \& Co. KGaA.

Fig. 16. Left: schematic representation of the $\mathrm{CdTe} / \mathrm{CdS}$ quantum dot used to detect fingermarks on nonporous substrates (Becue et al. 2009). Right: representative fingermark detected using this technique with aluminium foil as substrate.

Fig. 17. Potential outer shell functionalization of a silica nanoparticle with the objective of promoting the interactions with organic compounds such as amino acids and proteins in the secretion residue. 

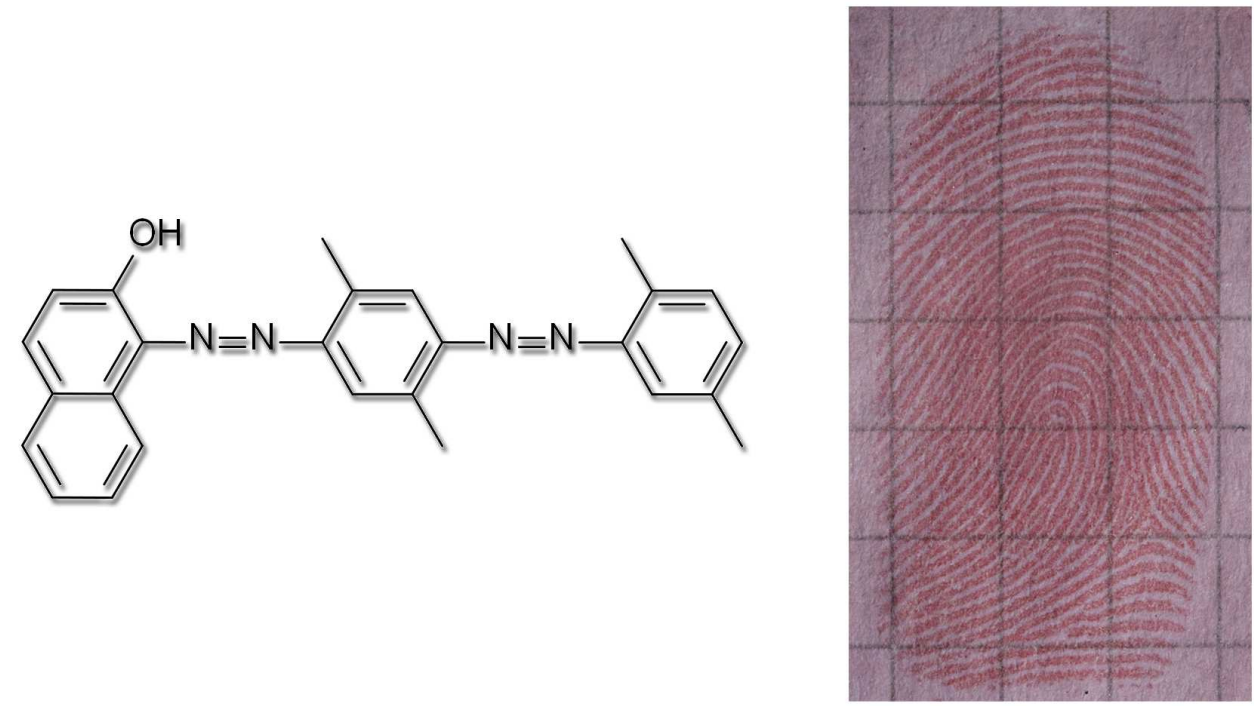

(Left) Molecular representation of Oil Red O; (Right) Representative fingermark detected using this technique (paper as substrate). $109 \times 61 \mathrm{~mm}(400 \times 400$ DPI $)$ 


\section{Polymerization mechanism taking place on the secretion residue during the cyanoacrylate fuming} process.

$133 \times 33 \mathrm{~mm}(400 \times 400 \mathrm{DPI})$

URL: http://mc.manuscriptcentral.com/tbih E-mail: biotech-histochem@louisville.edu 

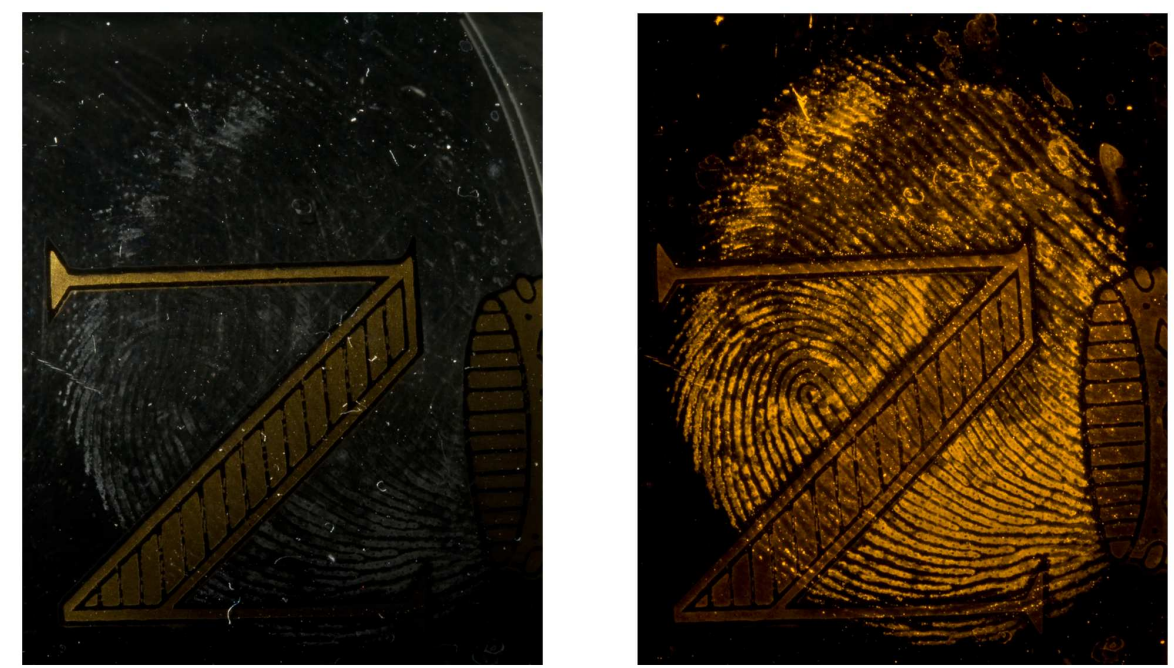

(Left) Cyanoacryle-fumed fingermark located on a beer glass (the quality of development is not optimal), (Right) Same fingermark after enhancement using Rhodamine 6G as cyanoacrylate dye (observation in luminescence). $140 \times 76 \mathrm{~mm}(400 \times 400 \mathrm{DPI})$ 
Chart illustrating the excitation and emission wavelength ranges for the most commonly used cyanoacrylate dyes. $99 \times 63 \mathrm{~mm}(300 \times 300$ DPI $)$

URL: http://mc.manuscriptcentral.com/tbih E-mail: biotech-histochem@louisville.edu 
<smiles>[R]C(N)C(=O)O</smiles><smiles>[R]C(N=c1c(=O)c2ccccc2c1=O)C(=O)O</smiles><smiles>[Os]</smiles><smiles>CC</smiles><smiles>[R]C=NC1C(=O)c2ccccc2C1=O</smiles><smiles>CCCCCCCCC</smiles><smiles>[C]1CCCCC1</smiles><smiles>O=C1c2ccccc2C(=O)C1(O)O</smiles>

Ninhydrin ( $2^{\text {nd }}$ molecule)

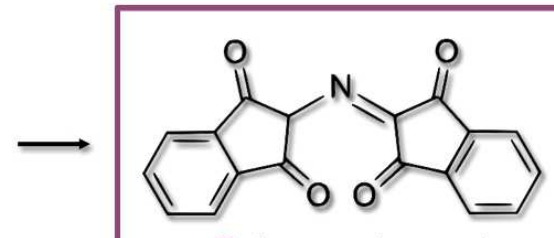

Ruhemann's purple

Reaction mechanism between Ninhydrin and amino acid, leading to the obtaining of a dark-purple product: the Ruhemann's purple. $99 \times 66 \mathrm{~mm}(300 \times 300 \mathrm{DPI})$ 

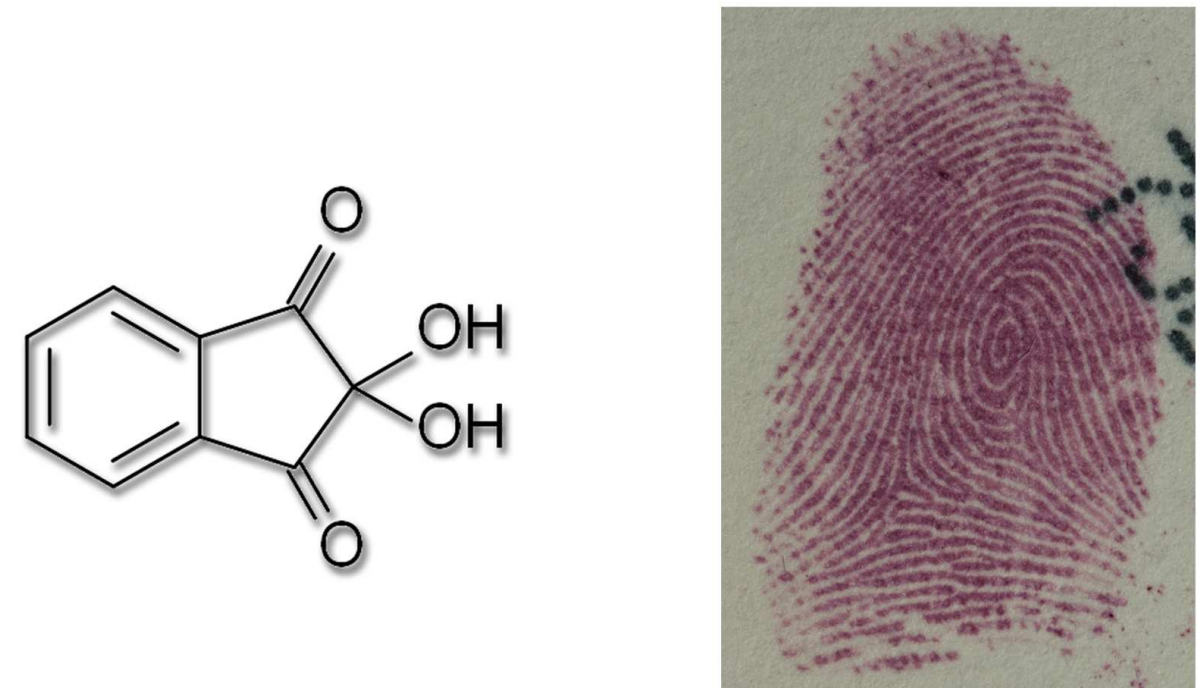

(Left) Molecular representation of Ninhydrin (2,2-dihydroxy-1,3-indanedione); (Right) Representative fingermark detected using this technique (paper as substrate). $109 \times 64 \mathrm{~mm}(400 \times 400$ DPI $)$ 

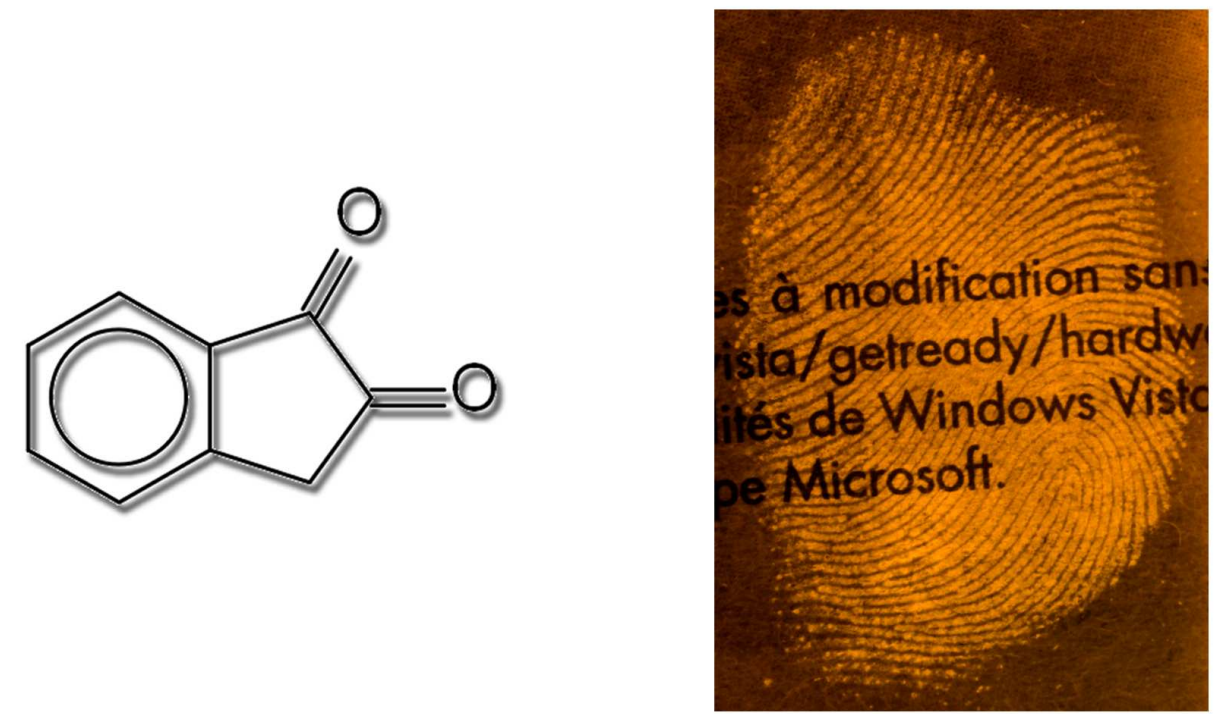

(Left) Molecular representation of 1,2-Indanedione; (Right) Representative fingermark detected using this technique (paper as substrate; observation in luminescence). $108 \times 64 \mathrm{~mm}(400 \times 400 \mathrm{DPI})$ 

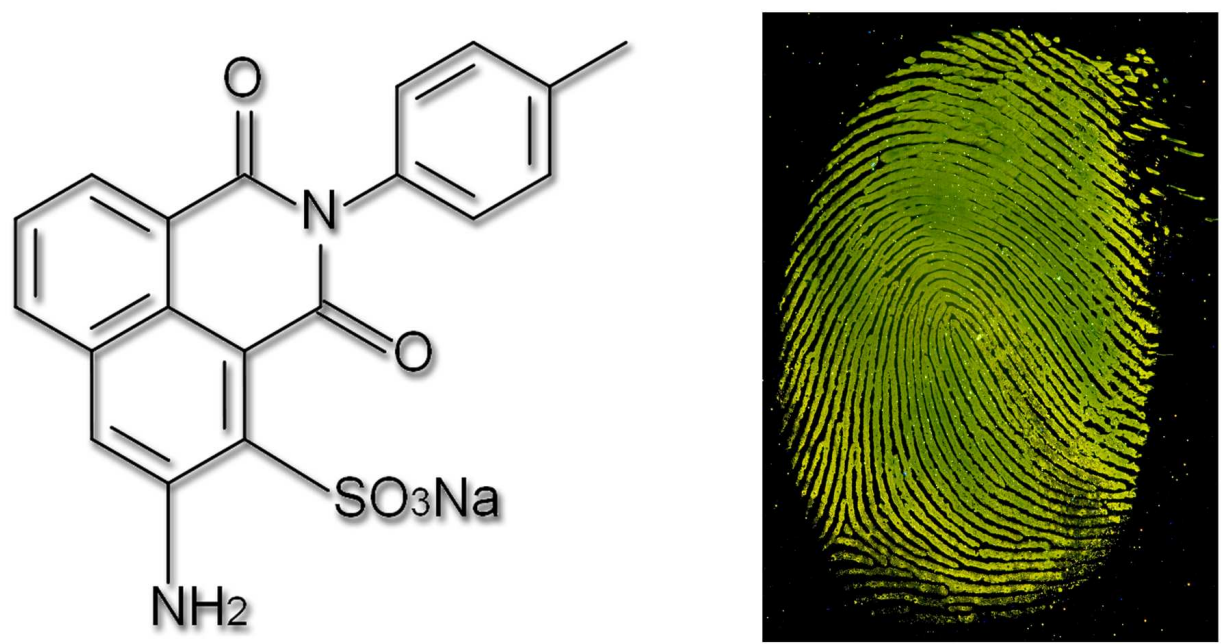

30

(Left) Molecular representation of Acid Yellow 7; (Right) Representative blood fingermark detected using this technique (aluminium foil as substrate).

$120 \times 64 \mathrm{~mm}(400 \times 400 \mathrm{DPI})$ 
Schematic illustration of the main characteristics of nanoparticles from which benefit should be taken to be used as fingermark detection reagents. A good contrast is obtained if the ridges are specifically targeted, and not the underlying substrate. $150 \times 118 \mathrm{~mm}(400 \times 400 \mathrm{DPI})$ 
Illustration of the functionalization strategy consisting in adding ligands on the outer surface of nanoparticles to increase their chemical potential in terms of affinity for the secretion residue. $200 \times 53 \mathrm{~mm}(400 \times 400$ DPI $)$

URL: http://mc.manuscriptcentral.com/tbih E-mail: biotech-histochem@louisville.edu 
Simplified illustration of the "two-steps" metal deposition application protocol. This chart is valid for multimetal deposition (MMD), single-metal deposition (SMD), and luminescent MMD (MMDlumin), which differ by the choice of the metal in the enhancement step: silver, gold, and zinc oxide, respectively.

$127 \times 39 \mathrm{~mm}(400 \times 400 \mathrm{DPI})$ 
MMD
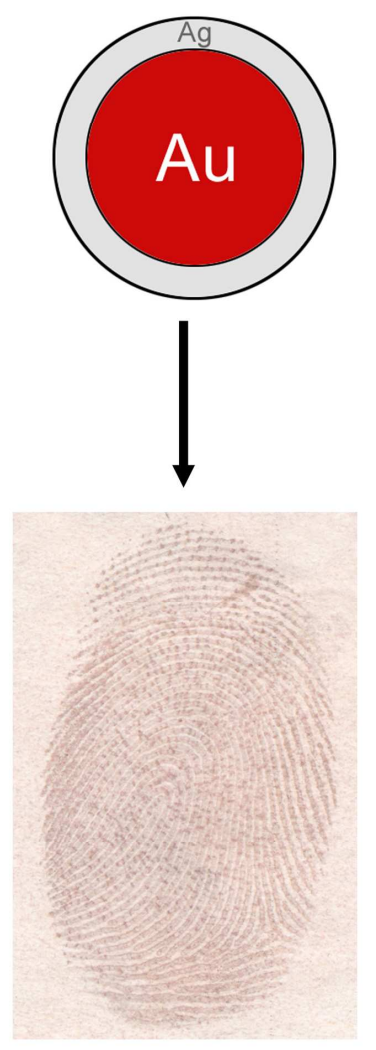

SMD
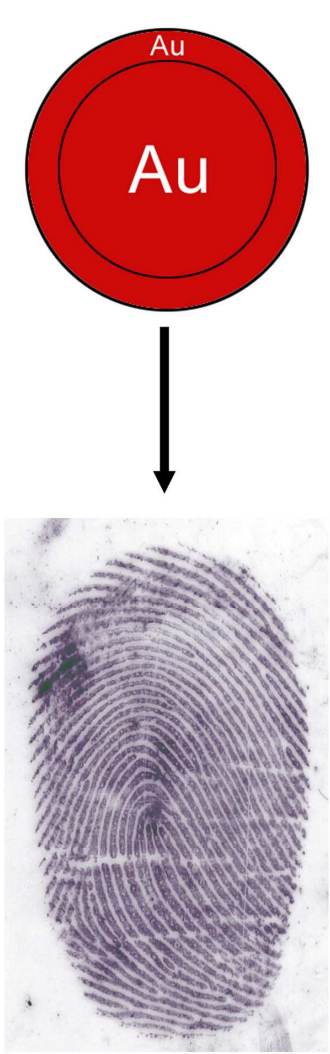

$\mathrm{MMD}_{\text {lumin }}$
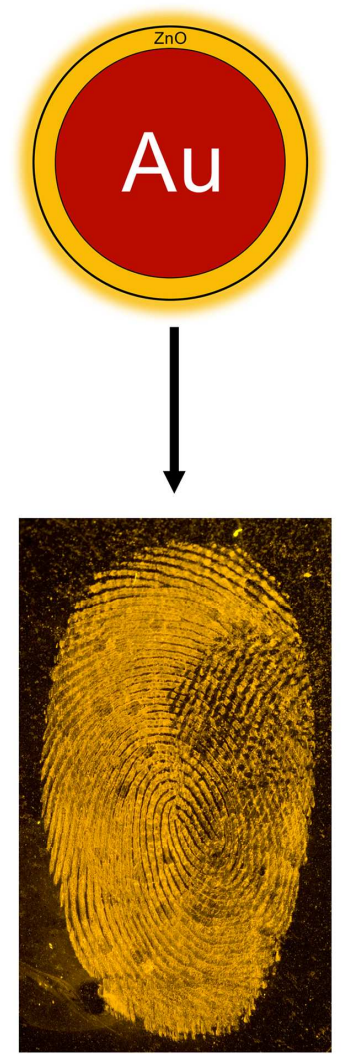

Schematic representation of the differences between the three metal deposition protocols in terms of final nanoparticle composition and detected fingermark aspect. Multimetal deposition (MMD) and single metal deposition (SMD) permit to obtained dark-coloured fingermarks, whereas luminescent MMD (MMDlumin) permits the observation of luminescent fingermarks.

$149 \times 138 \mathrm{~mm}(400 \times 400 \mathrm{DPI})$ 
Illustration of the two processes involved in the physical developer detection technique, according to the distance between the secretion residue and the colloid formation site ("in solution" or "close to the residue").

$175 \times 79 \mathrm{~mm}(400 \times 400 \mathrm{DPI})$ 
(Left) Schematic representation of the oleylamine-functionalized gold nanoparticle used as nanopowder to be dusted on fingermarks (Choi et al., 2006). (Right) Schematic representation of the alkanethiol-capped gold nanoparticle (Au-NP-C18) used to detect sebaceous fingermarks on porous and non-porous surfaces in an enhanced physical developer process (Sametband et al., 2007).

$190 \times 101 \mathrm{~mm}(400 \times 400 \mathrm{DPI})$

URL: http://mc.manuscriptcentral.com/tbih E-mail: biotech-histochem@louisville.edu 


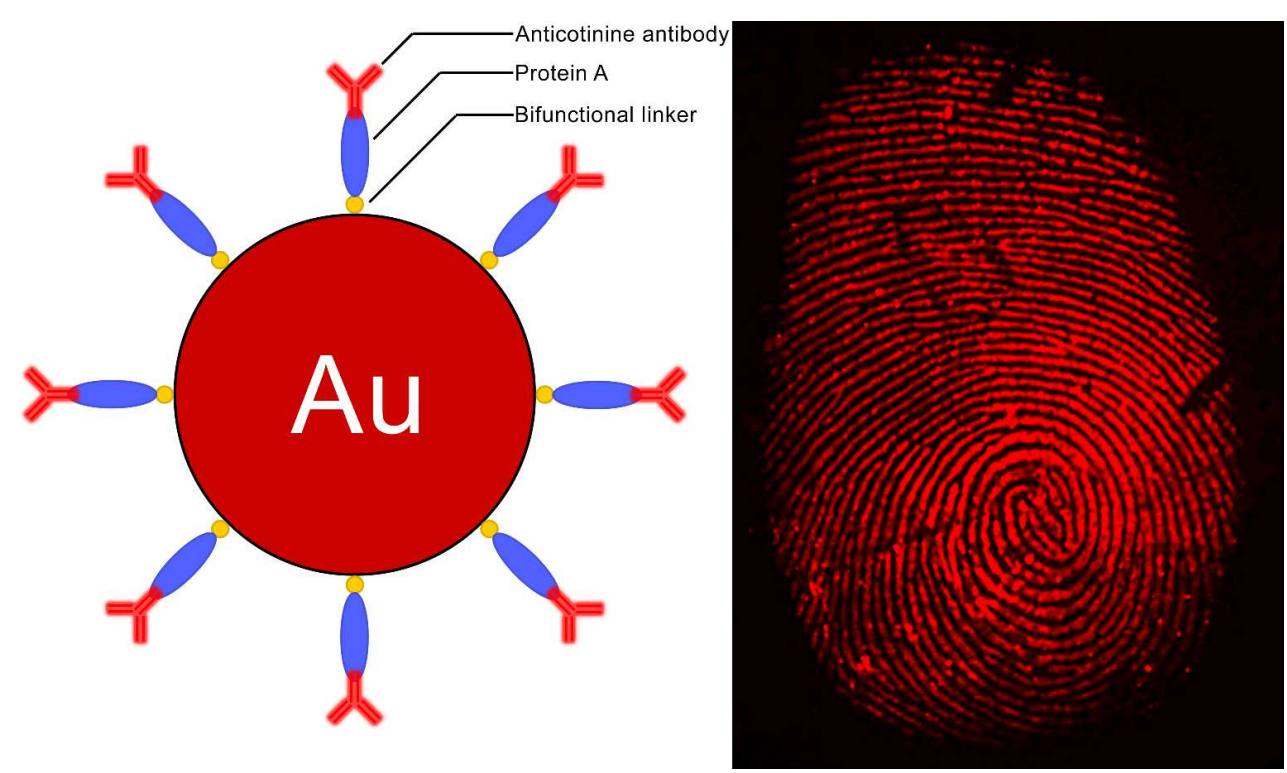

Schematic representation of the "protein A / antibody"-functionalized gold nanoparticle used to detect fingermarks by taking benefit of the highly-specific antibody/antigen recognition process. The illustrated fingermark has been obtained from a male smoker after 40 min sweating and detected using the anti-cotinine-functionalized nanoparticles and Alexa Fluor 546 as luminescent marker (source of the fingermark: (Leggett et al., 2007)). $200 \times 114 \mathrm{~mm}(400 \times 400 \mathrm{DPI})$ 

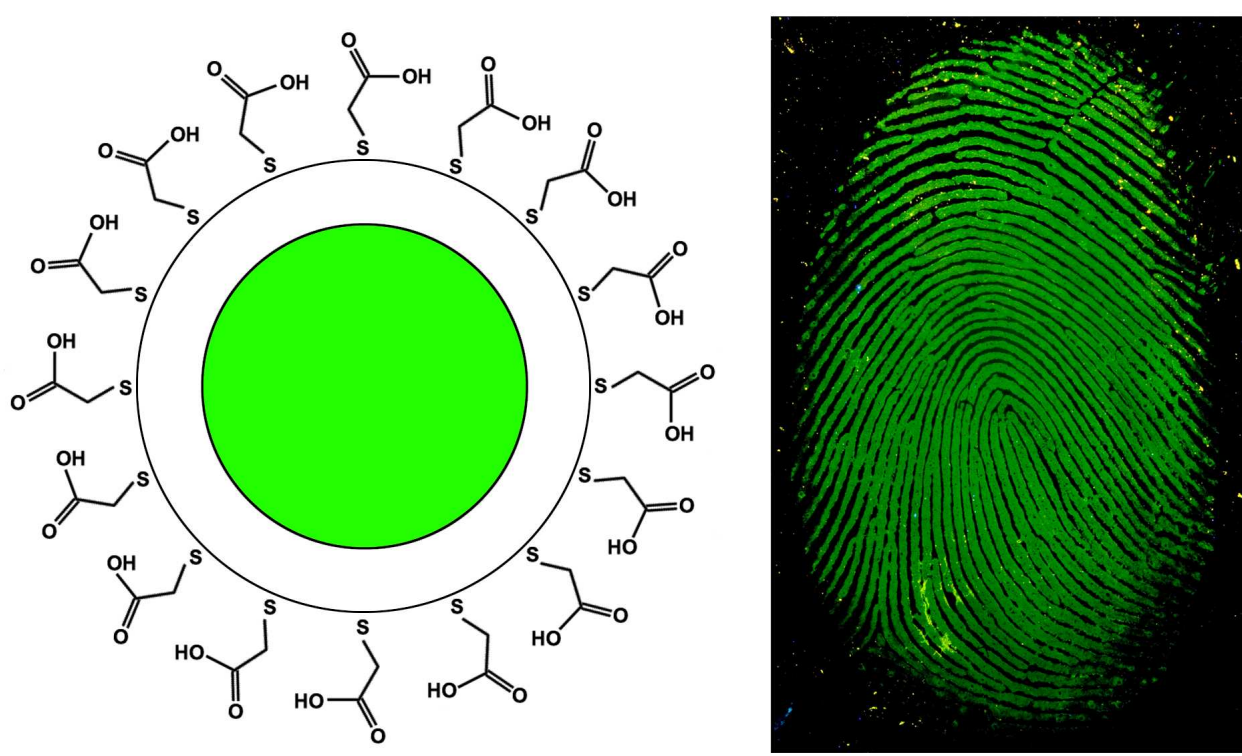

(Left) Schematic representation of the CdTe/CdS quantum dot used to detect fingermarks on nonporous substrates (Becue et al., 2009); (Right) Representative fingermark detected using this technique (aluminium foil as substrate). $123 \times 76 \mathrm{~mm}(400 \times 400 \mathrm{DPI})$ 

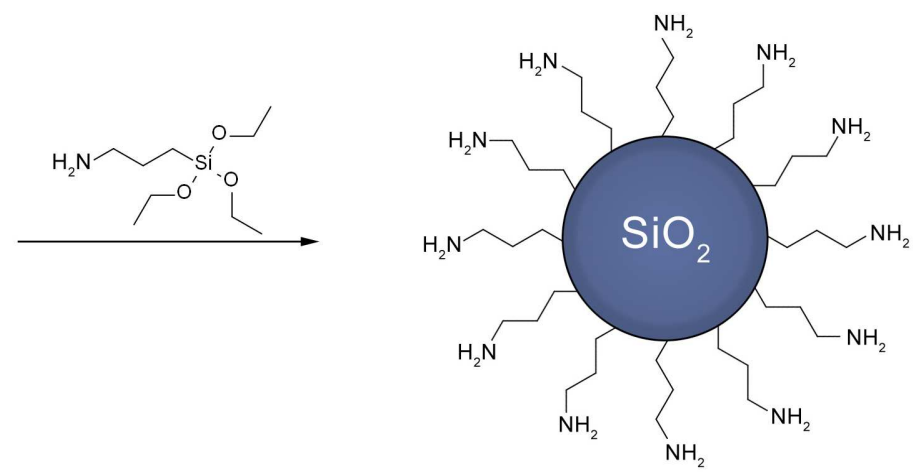

Potential outer shell functionalization of a silica nanoparticle having for aim to promote the interactions with organic compounds such as amino acids and proteins contained in the secretion residue.

$132 \times 52 \mathrm{~mm}(400 \times 400 \mathrm{DPI})$

URL: http://mc.manuscriptcentral.com/tbih E-mail: biotech-histochem@louisville.edu 